\title{
Katherine and the Katherine: On the syntactic distribution of names and count nouns*
}

\author{
Robin JESHION
}

Received: 30/04/2018

Final version: 11/07/2018

BIBLID 0495-4548(2018)33:3p.473-508

DOI: $10.1387 /$ theoria. 19588

ABSTRACT: Names are referring expressions and interact with the determiner system only exceptionally, in stark contrast with count nouns. The-predicativists like Sloat, Matushansky, and Fara claim otherwise, maintaining that syntactic data indicates that names belong to a special syntactic category which differs from common count nouns only in how they interact with 'the'. I argue that the-predicativists have incorrectly discerned the syntactic facts. They have bypassed a large range of important syntactic data and misconstrued a critical data point on which they ground the-predicativism. The right data offers new compelling syntactic grounds for referentialism.

Keywords: names, nouns, syntax, predicativism, reference.

RESUMEN: Los nombres son expresiones referenciales e interactúan con el sistema determinador sólo excepcionalmente, en fuerte contraste con los nombres contables. Descripto-predicativistas como Sloat, Matushnasky, y Fara afirman, sin embargo, que los datos sintácticos indican que los nombres pertenecen a una categoría sintáctica que difiere de los nombres comunes contables sólo en el modo en que interactúan con el descriptor ('el' o 'la'). Defiendo que los descripto-predicativistas no han valorado correctamente la evidencia sintáctica. No han tenido en cuenta varios tipos de datos y han malinterpretado un dato crítico fundamental sobre el que han fundamentado el descripto-predicativismo. La evidencia aportada ofrece nuevos y contundentes fundamentos sintácticos para el referencialismo.

Palabras clave: nombres, sustantivos, sintaxis, predicativismo, referencia.

* Since I met her just over twenty years ago, I have admired Delia's dazzling mind and spirit-her verve. When she got sick, I was struck by her strength and openness. I cherish my memories of her.

Delia's brilliant work on names as predicates ignited much of my own recent work on this topic. While we saw the philosophical landscape differently, our conversations in print and in personal correspondence constantly inspired me. I know that at the time of her death, she had at least two papers in the works extending our debate. It is a great sadness to me not to be able to continue our intense and illuminating discussions.

For fruitful exchanges and critical feedback, warm thanks to audiences at the University of Stockholm, University of Barcelona, the 2016 Eastern APA in Washington, and the Institut Jean Nicod, and to Kent Bach, Laura Delgado, Manolo García-Carpintero, Kathrin Gluer Pagin, Wolfram Hinzen, Genoveva Martí, Michael Nelson, Peter Pagin, Alex Radulescu, and Anders Schoubye. Thanks also to an anonymous referee for several fine suggestions which helped improve this paper. 


\section{The problem}

'Katherine' as it occurs in [1]-[2] is a proper name.

[1] Katherine wants coffee.

[2] Have you met Katherine?

To this, everyone agrees. Are 'Katherine' and 'Katherines', as they occur in [3]-[4], also proper names?

[3] Only one Katherine wants coffee.

[4] Have you met the two Katherines?

To this, controversy persists. It is the fundamental point dividing referentialism and predicativism about proper names.

Referentialism is the thesis that names are referring expressions. The semantic contribution of a name is just its referent. In a context of use, names contribute individuals to the propositions expressed by sentences in which they occur. Names are of semantic type $e$. This analysis of referentialism is compatible with both a Millian account of names as assigned individual constants as well as indexicalist or variabilist accounts on which names are assigned referents in the context of use.

Referentialism offers an attractive explanation of why 'Katherine', as it occurs in our first set of sentences, is a name. Since 'Katherine' occurs bare in the singular and occupies argument position, it can contribute an individual to the proposition expressed by each sentence. Yet 'Katherine' and 'Katherines', as they occur in our second set, cannot be referring expressions. They must have a predicate-type semantic value. So referentialists cannot construe them as having the same type of meaning as 'Katherine' has in the first set. They therefore ought to maintain that in these occurrences, the expressions are not names.

Predicativism is the thesis that names have a predicate-type semantic value in all of their occurrences. Names are a type of count noun and receive the same semantic value as other count nouns. So if the semantic value of common count nouns is best construed extensionally, as a function from individuals to truth values, names' semantic value is extensional, and names are of semantic type $\langle e, t\rangle$. If the semantic value of common count nouns is best construed intentionally, as encoding properties, say, names' semantic value is intentional, and they encode properties. Whether the semantic value of count nouns is best accounted for extensionally or intentionally is a matter orthogonal to predicativism. I shall freely trade between extensional and intentional meaning analyses of predicates. ${ }^{1}$

According to predicativism, in both sets of sentences, 'Katherine' is a name and is univocal, meaning (roughly) individual who bears the name 'Katherine'. For the first set, predicativists maintain that 'Katherine' does not actually occur in argument position. It only appears to do so because some of its syntactic structure is covert. In such occurrences, it constitutes rather the predicative component of a determiner phrase with a null (unpronounced and unwritten) determiner. According to that-predicativism, the null determiner

1 This characterization of predicativism is due to Fara (2015a). 
is 'that'. According to the-predicativism, my primary focus, the null determiner is 'the'. For the-predicativism, the actual syntactic structure of sentences [1], [2] is:

[5] $\varnothing_{\text {the }}$ Katherine wants coffee.

[6] Have you met $\varnothing_{\text {the }}$ Katherine?

For referentialism, only those sentences in our first set contain names. For predicativism, all of them do. Which theory is superior? And is there any evidence that could strongly favor one theory over the other?

Ora Matushanky and Delia Graff Fara think so. Inspired by Clarence Sloat's (1969), each advance a novel case on behalf of the-predicativism grounded in syntactic data. They maintain that a certain set of distinctive syntactic data powerfully suggests that names are a special variety of count noun. According to them, the data demonstrates that names share almost exactly the same distribution with the determiner system as that of common count nouns. The two sole distributional differences concern names' interaction with the definite article. This critical data, they say, is telling, and best explained by the existence of a nulldefinite article 'the' preceding bare singular names. To them, the syntactic distribution of names strongly favors the-predicativism over both that-predicativism and referentialism. ${ }^{2}$ I call Sloat, Matushansky, and Fara's argumentative strategy the Syntactic Rationale for Predicativism. ${ }^{3}$

Two general, complimentary tenets underwrite this rationale. One is that names are, in part, characterized by their distinctive syntax. The other is that discerning a wide range of syntactic data is needed to point us toward the best theory of names.

With Matushansky and Fara, I too champion both of these tenets. However, I believe that they, following Sloat, are wrong about what the syntactic facts are; and, further, they have neglected an important range of syntactic data that conflicts with predicativism. The burden of this paper is to present the right syntactic data and demonstrate why it drives us toward a referentialist theory that construes bare singular occurrences of 'Katherine' in [1]-[2] as names and the predicative occurrences in [3]-[4] as homonymous count nouns. Because of its structural similarity to the Sloat-inspired argument, call this argument the Syntactic Rationale for Referentialism.

Others have proposed positive analyses of names similar to my own, positing two syntactic categories, names and count nouns, to explain the phenomena. What distinguishes my discussion here is not the view but the case I advance in its favor. What most fellow referentialists have overlooked is that positing two syntactic categories commits one to a large

2 See Matushansky $(2005,2006,2015)$ and Fara (2015a, 2015b).

3 This rationale differs from others in favor of predicativism, in particular the Uniformity Rationale championing theoretical advantages of securing semantic uniformity across our two sets of examples. Fara (2015a) explicitly construes the Syntactic Rationale for Predicativism as an independent consideration favoring the-predicativism. Matushansky's (2006) argument is independent of uniformity considerations. For discussion of uniformity arguments, cf., Burge (1973), Guerts (1997), Bach (2002), Elugardo (2002), Elbourne (2005), Sawyer (2010). For analyses of why uniformity falls short, cf., Rami (2013) and Jeshion (2015a, 2015b, 2015c). While my focus here is on syntax, not semantics, the perspectives in the papers are complementary. 
set of syntactic data that tells against predicativism and demonstrates the power of referentialism. ${ }^{4}$

I shall argue for the following theses:

Referentialism--Semantics: Names are referring expressions. In a context of use, names contribute individuals to the propositions expressed by sentences in which they occur.

Referentialism--Syntax: Names interact with the determiner system only exceptionally; when names do combine with determiners, they do so in a highly specialized fashion, markedly different from that of count nouns.

I also argue that Referentialism-Syntax, a thesis inspired by Chomsky's conception of names as 'nouns with no determiners', is explained by Referentialism-Semantics (Chomsky 1965, 100). The limited syntactic interaction of names with the determiner system is accounted for by their status as referring expressions. ${ }^{5}$

An overview: $\$ \$ 2-3$ lay out the initial syntactic data for Referentialism-Syntax. $\$ 4$ details the central elements in the-predicativist's Syntactic Rationale. $\$ 5$ compares our alternative accounts of the syntactic data and reveals that one data point crucial to both positions can be decided on independent grounds. $\$ 6$ demonstrates that the key grammaticality judgment of the-predicativist's Syntactic Rationale is false. $\$ \$ 7-13$ detail a host of new syntactic data supporting names and count nouns' differential interaction with demonstratives, possessive pronouns, bare expressives, and various modifiers, offering further support for Referentialism-Syntax. Finally, $\$ 14$ consolidates the overarching syntactic argument in favor of referentialism and highlights its power by contrasting it with an alternative approach by fellow-referentialists.

\section{Referentialism: The syntactic distribution of names and count nouns}

Names are referring expressions. In each context of use, they have referential purport. If they have a referent, they contribute that referent, a particular individual, to the proposition expressed by the sentence. Names are of semantic type $e$.

4 Borer (2005) also distinguishes two categories, names and count nouns, and emphasizes syntax, as does Hinzen (2016). King (2006) offers what he calls an Ambiguity View. Some of King's arguments emphasize important syntactic considerations, especially those involving 'one'-anaphora. The novelty and power of my argument resides in the syntactic data's comprehensiveness. In saying that my case differs from proposals by fellow-referentialists, I have in mind those by others responding directly to Matushansky and Fara, including Leckie (2013) and Schoubye (2017). See footnote 21 and $\$ 14$.

Others have advanced specific versions of referentialism: variabilism (Cumming 2008); indexicalism (Pelczar and Rainsbury 1998); Millianism with Fregean presuppositions (García-Carpintero 2017); polyreferentialism (Delgado 2018), which can be seen as developing ideas in Perry (2012).

5 Cross-linguistic comparisons are important within the larger debate over names' syntax and semantics, and evidence from languages other than English is discussed cursorily within the dialectical in $\$ 6$. However, here I confine my argument to discerning the status of names' syntax and semantics within English, as do Sloat and Fara. While Matushansky addresses cross-linguistic evidence (2005, 2006, and 2015), the bulk of her data concerns English. She claims that overall, the data favors predicativism, yet this has been disputed by Longobardi (1994), Borer (2005), Hinzen (2016), and Delgado (2018). 
Count nouns are predicate expressions. Their semantic function is to express properties of individuals. When they are combined with certain determiners like 'that', 'this', and 'the', the whole determiner phrase can refer to a particular individual. But their semantic contribution to the determiner phrase is a property. Count nouns are of semantic type $\langle e, t\rangle$.

Names are not count nouns. This is exhibited by their starkly different syntactic distribution with the determiner system. Count nouns admit of pluralization, take quantifiers and numerical determiners, freely combine with indefinite and definite articles and deictic demonstratives, and can occur as generics. They cannot occur bare, unaccompanied by a determiner, in the singular, as shown in [7]:

[7] * Cat wants water.

Names exhibit the opposite behavior:

[8] *A Katherine wants coffee.

[9] *Some Katherines want coffee.

[10] Katherine wants coffee.

These grammaticality judgments may seem strange, for [8] and [9] initially strike one as grammatical. Yet this sense results only from interpreting 'Katherine', which I stated was here a name, as a (homonymous) count noun. After all, [8] and [9] are grammatical when 'Katherine' occurs as a count noun meaning individual who bears the name 'Katherine'. Yet in such circumstances, as in [3]-[4], 'Katherine' is not a name. There it has a predicate-type semantic value. Its status as a count noun is supported by the fact that it applies to individuals that are countable. Just as 'cat' applies to countable individuals (to wit: cats), so too does 'Katherine' (Katherines). It is also supported by its parallelism with other count nouns with respect to its syntactic distribution, for it pluralizes, takes quantifiers and numerical determiners, etc., and, in particular, is ungrammatical when it occurs bare in the singular. ' Katherine wants coffee' is ungrammatical when 'Katherine' occurs as a count noun, though it may look and sound grammatical because 'Katherine', defined purely orthographically and phonologically, frequently occurs as a proper name. The count noun 'Katherine' shares exactly the same syntactic distribution with the determiner system as other count nouns.

\section{Many count nouns look and sound like names}

We have seen that a single expression (characterized orthographically or phonologically) can occur as a name and as a count noun; that a sentence's grammaticality depends upon whether its contained expressions occur as names or count nouns; and that our grammaticality judgments depend upon how we interpret those expressions. These facts should encourage no dissent.

I once had a cat whose name was 'Cat'. 7 If, when I utter [11], I am speaking about my cat, Cat, 'Cat' occurs as a proper name, so [11] is grammatical.

[11] Cat wants water.

6 Fara advances these points as reasons for regarding names as count nouns.

7 True, by the way. 
The fact that the sentence has a reading on which it is ungrammatical, when 'cat' occurs as a count noun, does not impinge upon the fact that it is grammatical when 'Cat' occurs as a name, and vice versa. ${ }^{8}$ These elementary points are common ground among referentialists and predicativists.

Various classes of expressions systematically occur as both names and count nouns. Expressions like 'Romanov', 'Kennedy', and 'Corleone' frequently occur as surnames, but also as count nouns applied to members of a certain family or dynasty. In [12] and [13], the italicized expressions are count noun occurrences with a predicate-type meaning. They have an extension containing all and only those related by blood, marriage, or adoption to the family of Irish descent renowned within American politics.

[12] Maria Shriver is a Kennedy.

[13] Chris Kennedy, the linguist, is not a Kennedy.

When they are applied to members of a certain family, these expressions are sometimes dubbed 'family names'. But they are not names.'

Expressions like 'Tesla' and 'Leica' occur systematically both as names of companies and as count nouns applied to companies' products (cars, cameras). When applied to products, as in [14] and [15], they are often dubbed 'brand names'. They too are not names.

[14] The Tesla I test-drove was amazing.

[15] Leicas are expensive.

To refer to these classes of count nouns, I shall henceforth speak of family 'names' and brand 'names', flagging 'names' with scare quotes. The fact that family and brand 'names' are systematically related to surnames and names of companies, respectively, has no bearing on the syntactic classification of the former as count nouns and the latter as names.

What I want to drive home is this: Exactly the same obtains for 'Katherine'. Although the count noun occurrences of 'Katherine' are systematically related to the name occurrences, that fact has no bearing on their syntactic classification. I shall henceforth refer to them as collective 'names'. Collective 'names' are not names. ${ }^{10}$

8 'Cat' is, of course, not anomalous. Numerous expressions frequently occur as both names and count nouns, as the given names of Rose Kennedy, Crystal Gayle, and Forest Whitaker testify.

9 Family 'name' count nouns are pervasive, not restricted to famous families. Consider: a dinner invitation to the Robinsons by the Braddocks.

10 A note on terminology and polysemy. In this paper, I am using 'name' and 'count noun' mutually exclusively to reflect their differential syntactic distribution with the determiner system. On this terminology, if an expression occurs as a count noun, it is, in that occurrence, a count noun, even if its count noun status is derived from a name. So, e.g., I say that 'Picassos' in 'Are there any Picassos in The Prado?' is a count noun, even though it is derived from the name of Pablo Picasso. On an alternative terminology, one could say that here 'Picassos' is a name being used as a count noun. An advantage of my terminology is that it allows me to avoid taking a stand on whether in examples like [1] and [3], there are two (merely) homophonous expressions, the name $N$ having an individual as its semantic value and the collective 'name' $N^{*}$ having a predicate-type semantic value, or a single expression that has a use as a name and a use as a collective 'name'. My argument throughout does not depend on this issue. 
Because our subject matter involves displaying the syntactic properties of orthographically identical names and count nouns, it is useful to represent whether an expression is occurring as a name or a count noun. Henceforth, I use red typeface when an expression occurs as a count noun, blue when it occurs as a name. When discussing predicativists' perspective on all of the expressions they regard as names, I present the expressions in purple.

With these conventions, I offer a synthesis of my key claims thus far. The chart below details the syntactic distribution of the names 'Cat' and 'Katherine' (on the left) and the count nouns 'cat' and 'Katherine' (on the right). The distributions are radically distinct: those sentences containing the name 'Katherine' that are grammatical have a corresponding sentence containing the count noun 'Katherine' that is ungrammatical, and vice versa. ${ }^{11}$

\section{Referentialism: Names and collective 'name' count nouns}

\begin{tabular}{|l|l|l|l|}
\hline \multicolumn{2}{|c|}{ Names } & \multicolumn{2}{c|}{ Count Nouns } \\
\hline *A Cat wants water. & $\begin{array}{l}\text { *A Katherine wants cof- } \\
\text { fee. }\end{array}$ & A cat wants water. & A Katherine wants coffee. \\
\hline *Two Cats want water. & $\begin{array}{l}{ }^{*} \text { Two Katherines want } \\
\text { coffee. }\end{array}$ & Two cats want water. & $\begin{array}{l}\text { Two Katherines want cof- } \\
\text { fee. }\end{array}$ \\
\hline *Some Cats want water. & $\begin{array}{l}\text { *Some Katherines want } \\
\text { coffee. }\end{array}$ & Some cats want water. & $\begin{array}{l}\text { Some Katherines want } \\
\text { coffee. }\end{array}$ \\
\hline $\begin{array}{l}* \text { The Cat from the shelter } \\
\text { wants water. }\end{array}$ & $\begin{array}{l}\text { *The Katherine from yoga } \\
\text { class wants coffee. }\end{array}$ & $\begin{array}{l}\text { The cat from the shelter } \\
\text { wants water. }\end{array}$ & $\begin{array}{l}\text { The Katherine from yoga } \\
\text { class wants coffee. }\end{array}$ \\
\hline *Cats enjoy sleeping. & *Katherines are classy. & Cats enjoy sleeping. & Katherines are classy. \\
\hline *That Cat wants water. & $\begin{array}{l}\text { *That Katherine wants } \\
\text { coffee. }\end{array}$ & That cat wants water. & $\begin{array}{l}\text { That Katherine wants cof- } \\
\text { fee. }\end{array}$ \\
\hline *The Cat wants water. & $\begin{array}{l}\text { *The Katherine wants cof- } \\
\text { fee. }\end{array}$ & The cat wants water. & $\begin{array}{l}\text { The Katherine wants cof- } \\
\text { fee. }\end{array}$ \\
\hline Cat wants water. & Katherine wants coffee. & *Cat wants water. & *Katherine wants coffee. \\
\hline
\end{tabular}

To underscore the parity in distribution between collective, brand, and family 'names', I also offer a chart detailing the syntactic distribution of names of companies adjacent to the syntactic distribution of brand 'name' and family 'name' count nouns. ${ }^{12}$ Collective 'names' have the same distribution as family and brand 'name' count nouns.

11 The chart exemplifies the syntactic distribution of expressions receiving name and count noun interpretations. So, for instance, the line that exemplifies that bare count nouns are ungrammatical $-{ }^{*} \mathrm{Cat}$ wants water - precludes giving a mass noun interpretation to 'cat'.

12 Sloat $(1969,26)$ commits to this syntactic distribution of brand 'names' by taking words like 'Chevrolet', when understood as a type of car, to be 'ordinary countable nouns.' Fara (2015c) commits to the syntactic distribution for family 'names' by taking them to be common count nouns. 
Referentialism: Names and family/brand 'name' count noun

\begin{tabular}{|l|l|l|}
\hline \multicolumn{1}{|c|}{ Names } & \multicolumn{1}{|c|}{ Count Nouns (Brand 'Names') } & \multicolumn{1}{|c|}{ Count Nouns (Family 'Names') } \\
\hline *A Tesla developed a new model. & A Tesla is parked outside. & A Corleone is standing outside. \\
\hline $\begin{array}{l}\text { *Two Teslas developed a new } \\
\text { model. }\end{array}$ & She uses two Leicas. & She likes two Romanovs. \\
\hline $\begin{array}{l}\text { *Some Teslas developed a new } \\
\text { model. }\end{array}$ & Some Leicas have slow shutters. & Some Corleones carry guns. \\
\hline $\begin{array}{l}\text { *The Leica from Germany makes } \\
\text { cameras. }\end{array}$ & The Tesla I test-drove is amazing. & $\begin{array}{l}\text { The Romanov I met is fascinat- } \\
\text { ing. }\end{array}$ \\
\hline $\begin{array}{l}\text { *Leicas offers employees solid ben- } \\
\text { efits. }\end{array}$ & Leicas are expensive. & Corleones are dangerous. \\
\hline *That Leica makes cameras. & That Leica needs refurbishing. & That Romanov needs coffee. \\
\hline *The Tesla makes cars. & The Tesla is parked outside. & The Romanov wants coffee. \\
\hline Tesla developed a new model. & *Tesla is parked outside. & *Romanov wants coffee. \\
\hline
\end{tabular}

This data itself provides compelling evidence for Referentialism about Names-Syntax. $\$ \$ 8-13$ detail substantially more with a broader range of determiners and modifiers.

I expect that many will find this data intuitively compelling, so much so that its status as novel evidence may be overlooked. Theorists have not previously articulated and advanced the restricted interaction of names with determiners as evidence against predicativism. Yet this data is significant and controversial. As we will see momentarily, the-predicativists will-and must_object to at least one item in every row for the two 'Katherine' columns. They must collapse our dual distributions into a single distribution. But there are two interpretations for each sentence, just as there are for sentences containing 'cat', 'Tesla', and 'Romanov', and their differential grammaticality is discernable. In the first seven lines, if one interprets 'Katherine' as a name, one can detect the ungrammaticality, just as one can detect the ungrammaticality in the last line if one interprets 'Katherine' as a count noun. But both are, I grant, difficult to establish by themselves, straightaway, on theory-neutral grounds.

\section{The syntactic rationale for the-predicativism}

The-predicativists advance as evidence for the Syntactic Rationale for Predicativism a markedly different set of syntactic data. Consider the following chart: ${ }^{13}$

13 The top contains Sloat's originals, altered only by the choice of examples. The last three lines are Fara's additions. 'Some' is the unstressed 'some' that occurs with plurals and mass nouns; 'some' is the stressed 'some' typically captured by the existential quantifier. 'THE' is the heavily stressed definite, typically used to indicate a famous, well-known, or most salient individual. (Sloat 1969; Matushansky 2014; Fara 2015a). 
The (adapted) sloat chart

\begin{tabular}{|l|l|}
\hline A cat wants water. & A Katherine wants coffee. \\
\hline *Some cat wants water. & *Some Katherine wants coffee. \\
\hline Some cat wants water. & Some Katherine wants coffee. \\
\hline Some cats want water. & Some Katherines want coffee. \\
\hline Some cats want water. & Some Katherines want coffee. \\
\hline Cats enjoy sleeping. & Katherines are classy. \\
\hline The clever cat wants water. & The clever Katherine wants coffee. \\
\hline The cat from the shelter wants water. & The Katherine from yoga-class wants coffee. \\
\hline A clever cat wants water. & A clever Katherine want coffee. \\
\hline The cats want water. & The Katherines want coffee. \\
\hline The cat wants water. & *The Katherine wants coffee. \\
\hline *Cat wants water. & Katherine wants coffee. \\
\hline
\end{tabular}

Fara's additions

\begin{tabular}{|l|l|}
\hline That clever cat wants water. & That clever Katherine wants coffee. \\
\hline *That cats want water. & *That Katherines want coffee. \\
\hline That cat wants water. & That Katherine wants coffee. \\
\hline THE cat wants water. & THE Katherine wants coffee. \\
\hline
\end{tabular}

The Syntactic Rationale for The-Predicativism begins with the observation that there exists nearly perfect parallelism between the syntactic behavior of count nouns and names. According to proponents, the chart reveals that Chomsky was radically mistaken in construing names as resisting determiners. Names richly interact with determiners-in fact, nearly identically to how count nouns do. There exist just two divergences in the syntactic patterning: unmodified count nouns can occur in the singular directly preceded by unstressed 'the', yet unmodified names cannot; and count nouns cannot occur bare in the singular, yet names can.

Predicativist proponents of the syntactic rationale maintain that there is a powerful, indeed compelling, way to explain this data. By positing that names occurring as bare singulars are fronted by an unpronounced yet syntactically real determiner 'the', we can restore an exact match in syntactic distribution with count nouns. The only differences between them occur at the surface-level, concerning whether 'the' is pronounced or written. Thus, as Sloat noted, names are 'only trivially distinct' from ordinary count nouns with respect to determiner selection (Sloat 1969, 30). 
Sloat, Matushanksky, and Fara's Syntactic Rationale for The-Predicativism may be fruitfully clarified by distinguishing four claims. Three are typically presented as theory-neutral data.

Parallel Syntax consist in an observation about the chart itself and an extension from it. The observation is that with only two exceptions, the patterning of determiner selection of all occurrences of 'Katherine' and 'Katherines' within the chart parallels that of common count nouns. ${ }^{14}$ The extension from it is that nearly all other combinations with determiners and modifers, i.e., those that are not on the chart, manifest parallelism as well. I say 'nearly' because, as Sloat, Fara, and Matushansky each acknowledge, adjectives can occur prenominally without an overt article, as in 'I talked to young Martin about it'. Yet they all regard this data point as a curious inexplicable exception to their respective theoretical analysis of how 'the' patterns with names. (See $\$ \$ 10-11$ below.) Thus, they conclude, the only significant exceptions to complete parallelism in syntactic distribution reside in the last and penultimate lines of the Sloat chart.

Univocity is the claim that all occurrences of 'Katherine' and 'Katherines' in the chart are proper names. For the argument's proponents, Univocity and Parallel Syntax, taken together, provide compelling syntactic evidence for taking names to be count nouns.

Deviating Syntax specifies the two deviations in syntactic parallelism:

\begin{tabular}{|l|l|}
\hline The cat wants water. & *The Katherine wants coffee. \\
\hline *Cat wants water. & Katherine wants coffee. \\
\hline
\end{tabular}

Deviating Syntax (I): Common count nouns can occur in the singular directly preceded by the unstressed definite 'the', without being followed by a relative clause; name count nouns cannot.

Deviating Syntax (II): Common count nouns cannot occur bare in the singular; name count nouns can.

The fourth claim, Null Determiner: 'the' is the-predicativist's theoretical posit that when names occur as bare singulars, they are fronted by a covert determiner, the definite article 'the'. Null Determiner: 'the' serves two functions, one semantic, one syntactic. Semantically, it ensures that in bare singular occurrences, 'Katherine' can mean individual who bears the name 'Katherine', the predicative contribution to the determiner phrase. Syntactically, Null Determiner: 'the' functions to reveal as trivial names' deviations in distribution from count nouns'. Positing a null determiner 'the' to front names precisely when they occur as bare singulars in argument position restores distributional parallelism: ${ }^{15}$

$$
\text { The cat wants water. } \quad \leftarrow \rightarrow \varnothing_{\text {the }} \text { Katherine wants coffee. }
$$

${ }^{14}$ Matushansky $(2006,289)$ claims her view predicts names have the syntax of count nouns (barring exceptions).

${ }^{15}$ Fara (2015a, 71) draws parallels of this type, offering among others:

The table is tall. $\leftarrow \rightarrow \emptyset_{\text {the }}$ Maria is tall. 
By inserting the null occurrence of the determiner within the chart thus

\begin{tabular}{|l|l|}
\hline The cat wants water. & $\begin{array}{l}\emptyset_{t h e} \text { Katherine wants coffee. } \\
\text { *The Katherine wants coffee. }\end{array}$ \\
\hline${ }^{*}$ Cat wants water. & \\
\hline
\end{tabular}

we can see the differences to be trivial, concerning only whether 'the' is overt or covert. Similarly, Null Determiner 'the' ensures that singular names cannot occur bare, just like ordinary count nouns. Though they may appear to do so, surface-level bare names are in fact fronted by the covert definite. ${ }^{16}$ Our chart represents this absence of a surface-level ungrammatical correlate to 'Cat wants water' with the empty box on the right. Thus, for thepredicativists, Null Determiner 'the' reveals that at the level of logical form, names possess the same distribution with determiners as other count nouns. To mark off names' syntactic class but also their surface level differences, proponents often distinguish two subtypes of count nouns, what Fara dubs common count nouns and name count nouns (Fara 2015a, 78-79, 108).

To condense presentation of the Syntactic Rationale, I'll call sentences like 'The Katherine wants coffee' and 'The Smith stopped by' The Katherine sentences (regardless of whether they contain 'Katherine'). I'll call sentences like 'Katherine wants coffee' and 'Smith stopped by' Katherine sentences. Recast with this terminology, we have:

Univocity: All the sentences on the right of The Sloat Chart contain names. In particular, both The Katherine sentences and Katherine sentences contain names.

Parallel Syntax: Names exhibit the same patterning of determiner selection as common count nouns, with the exceptions of The Katherine sentences and Katherine sentences.

Deviating Syntax: (I) The Katherine sentences are ungrammatical, in contrast with parallel common count noun constructions, which are grammatical. (II) Katherine sentences are grammatical, in contrast with parallel common count noun constructions, which are ungrammatical.

Null Determiner: 'the': Katherine sentences contain the null determiner ' $\emptyset_{\text {the }}$ ' directly preceding the name.

Syntactic Rationale for Predicativism: Univocity, Parallel Syntax, and Deviating Syntax together show that names have a distinctive patterning of determiner selection that cannot be satisfactorily explained without Null Determiner: 'the'.

Notice how important the ungrammaticality of The Katherine sentences is to this Syntactic Rationale. As we saw, proponents' reason for positing a null determiner turns essentially upon construing Katherine sentences as the name count noun correlate of 'The cat wants water', justified because The Katherine sentences are ungrammatical. Since predicativists interpret 'Katherine' as contributing the same predicative meaning in both Katherine and The Katherine sentences, for them, were the latter grammatical, the two would be synonymous. Thus, they regard The Katherine sentences as ungrammatical precisely

${ }^{16}$ Fara (2015a, 94): 'Singular count nouns cannot occur bare in an argument position, but when they appear to do so they occupy the predicate position of a denuded definite description.' 
because 'the' is overt, in conflict with what they see as its compulsory covertness as in Katherine sentences. ${ }^{17}$

The Katherine sentences are also central to the-predicativist's explanation of why 'the' occasionally occurs covertly. Fara offers an explanation in terms of a rule:

Where ' $\varnothing_{\text {the }}$ ': The definite article will appear as null before names, except when it is heavily stressed or when the names are preceded by modifiers or followed by restrictive modifiers.

Where ' $\varnothing_{\text {the }}$ ' When a name occurs in a definite description, the definite article must be unpronounced when the name is its structural sister, unless the definite article is stressed (Fara 2015b, 4-5).

The first version essentially synthesizes her data. The second generalizes the data, and accounts for the anomalous covertness as a morphological merger. ${ }^{18}$ In virtue of its explanatory generality and simplicity, Fara sees $W$ here ' $\varnothing_{\text {the }}$ ' as providing the strongest evidence for the-predicativism (Fara 2015a, 109).

Finally, the ungrammaticality of The Katherine sentences is essential to the-predicativists' construing their theory to be superior on purely syntactic grounds to both that-predicativism and referentialism. ${ }^{19}$ That-predicativism cannot explain away the curious syntactic distribution with a null determiner 'that', and referentialism would need a special story to explain why what they regard as an ordinary count noun has an eccentric distribution with 'the'.

\section{Predicativism meets referentialism}

Compare the syntactic data advanced by the-predicativists' with our own:

\section{Predicativism meets referentialism}

\begin{tabular}{|l|l|l|}
\hline A Katherine wants coffee. & A Katherine wants coffee. & *A Katherine wants coffee. \\
\hline Two Katherines want coffee. & Two Katherines want coffee. & *Two Katherines want coffee. \\
\hline Some Katherines want coffee. & Some Katherines want coffee. & *Some Katherines want coffee. \\
\hline $\begin{array}{l}\text { The Katherine from yoga class } \\
\text { wants coffee. }\end{array}$ & $\begin{array}{l}\text { The Katherine from yoga class } \\
\text { wants coffee. }\end{array}$ & $\begin{array}{l}\text { *The Katherine from yoga class } \\
\text { wants coffee. }\end{array}$ \\
\hline Katherines are classy. & Katherines are classy. & "Katherines are classy. \\
\hline That Katherine wants coffee. & That Katherine wants coffee. & *That Katherine wants coffee. \\
\hline *The Katherine wants coffee. & The Katherine wants coffee. & *The Katherine wants coffee. \\
\hline Katherine wants coffee. & *Katherine wants coffee. & Katherine wants coffee. \\
\hline
\end{tabular}

${ }_{17}$ Summarizing her analysis, Fara (2015a, 94) writes 'The definite article must appear overtly with singular names when it is stressed, when the name is preceded by a restrictive or nonrestrictive modifier (but for some exceptions [involving prenominal adjectives]...) or when the name is followed by a restrictive modifier; otherwise it is required to be null.' My emphasis.

${ }^{18}$ Matushansky also explains the distribution by positing a morphological merger.

19 Fara (2015a, 95) claims 'accounting for Sloat's distribution patterns requires that the null determiner... be the null definite article.' Matushansky $(2006,2014)$ and Sloat $(1969)$ offer similar arguments. 
Our sixteen data points reflect our countenancing two syntactic classes; the-predicativists' eight data points reflect their merging into a single class name count nouns-hence, the purple. ${ }^{20}$

Predicativists bypass numerous syntactic facts: for each sentence, there exists an interpretation for both the collective 'name' count noun and the name. Though the syntactic facts are compelling, admittedly, they cannot be definitively established in a theory-neutral fashion, as previously noted.

Our theory explains the-predicativists' first six lines of data by countenancing grammatical sentences containing collective 'name' count nouns. We differ in denying they are names. Our theory accommodates their last line by countenancing grammatical Katherine sentences so long as they contain names. On all these data points, our differences concern only differential classification of sentences we agree to be grammatical.

Of the-predicativist's penultimate line containing a The Katherine sentence, however, there exists a difference that is not due to differential classification. Whereas the-predicativists maintain that The Katherine sentences are ungrammatical, we are committed to their grammaticality when 'Katherine' is a collective 'name' count noun. After all, as the-predicativists correctly note, it would be strange, and a strike against referentialism, if collective 'names' had an anomalous interaction with 'the'. ${ }^{21}$

Thus, debate hinges in part on the grammaticality status of The Katherine sentences. They are, and can be established as such on theory-independent grounds. ${ }^{22}$

\section{The Katherine sentences are grammatical}

To establish The Katherine sentences as grammatical, I present three sets of cases.

\section{PARTY}

The Katherine: Colin Singleton has a thing for Katherines. He seeks and dates Katherines, is dumped by Katherines, and is constantly on the lookout for the next Katherine. ${ }^{23}$ Colin's Katherine fetish is known by his friend Hassan, and known by Colin to be known. Midway into a party, Hassan calls Colin saying "You've got to get on over here. There's someone you need to meet." Walking in the door and wasting no time, Colin asks:

[16] Where is the Katherine?

20 Thus, our syntactic data exhibits why it's incorrect to construe names and common count nouns as having nearly complete overlap in their distribution with the determiner system. In fact, for this range of determiners, there is no overlap at all.

${ }^{21}$ Referentialist theories construing collective 'names' as count nouns yet denying The Katherine sentences' grammaticality are unstable. By signing onto the-predicativist's version of the syntax of names, including the ungrammaticality of The Katherine sentences, Schoubye (2017) saddles (what he calls) predicative names with an unaccounted-for anomalous syntactic distribution.

22 The arguments in $\$ 6$ condenses but also elaborates on those presented in Jeshion (2015c, 2017).

23 The case is based on John Green's novel An Abundance of Katherines (Green 2006). 
The dancer: Alvin likes dancers. In a corresponding situation, Alvin asks:

[17] Where is the dancer?

\section{EXPERIMENT}

The Diego: A psychologist is investigating the relationship between the names people bear and their psychological profiles. Each morning, she administers a Myer-Briggs personality test to a Rafael, a Diego, and a Gabriel, and over lunch discusses her current experimental run with colleagues. Today she says:

[18] Once again, the Diego ranked high as an extrovert.

The Philosopher: Our researcher is investigating the relationship between occupations and psychological profiles, with daily tests given to an actor, an architect, and a philosopher. She comments:

[19] Once again, the philosopher ranked high as an introvert.

\section{Festival}

The Persephone: For a Greek names' festival, the Andromedas decide to show name-spirit and unity by wearing golden togas. They organize in a private communication, as do, similarly, the Persephones who agree to wear silver, and the Athenas, bronze. An astute festival reporter discerns the color-code, and, spotting a new person donning silver, says to a friend:

[20] I'm going to interview the Persephone.

The Stewart: At the Highland Games, a Scottsman who can match tartan plaids to their clan 'names' says:

[21] Have a look at the Stewart! He wears that kilt handsomely.

In each of the three cases, our speakers utter grammatical The Katherine sentences. To demonstrate, I've simply supersized the significance of the category expressed by the collective 'name' count noun within the life of my subjects, and then shown that the context and sentences uttered are no different in kind than their companions involving ordinary and family 'name' count nouns. In particular, I am not crafting atypical linguistic constructions or situations, only atypical proclivities, enquiries, festivities. Nothing about the communicative contexts or their being collective 'names' distinguishes them. This means we can expect that since ordinary and family 'name' count nouns combine unmodified with 'the', so too should-and do-our collective 'name' count nouns.

Predicativists have two main avenues for preserving their Syntactic Rationale. One is to deny the grammaticality of all The Katherine sentences. This option can be multi-pronged, explaining away different cases differently. Still, it requires showing all the cases to be defective, typically as demanding reinterpretation of the uttered sentences as involving richer syntactic structure. Call this The Reinterpretation Strategy. Another is to acknowledge that while there are some grammatical The Katherine sentences, a select class of such sentences are nevertheless still ungrammatical and then maintain that the null determiner they posit 
as fronting bare singular names is special, not identical to the English definite, and occurs only with names. Call this The Novel 'the $e^{* \prime}$ Strategy.

\section{$\$ 6.1$ THE REINTERPRETATION STRATEGY}

For The Reinterpretation Strategy, a natural move is to maintain that the sentences in our cases involve an implicit restrictive modifier:

[22] Where is the Katherine [you alluded to]?

[23] The Diego [from this morning's experiment] ranked high as an extrovert.

The problem is that, because the linguistic contexts are exactly analogous in the ordinary and family 'name' count nouns cases, and because the move to reinterpret cannot be ad hoc, enriched content must be added to those sentences as well.

[24] Where is the dancer [you alluded to]?

[25] Once again, the philosopher [from this morning's experiment] ranked high as an introvert.

There might well be non-ad-hoc grounds for enriching the content in some of our cases. But it will not work for all. There are abundant cases in which our speaker employ count nouns, unmodified, and they do not demand enriched implicit content. Because our cases involving collective 'names' are situationally exactly analogous, there will be corresponding non-enriched unmodified 'the'-fronted collective 'name' count nouns.

One response is to deny the collective 'name' cases can be situationally analogous: unlike other categories encoded as count nouns, they are unique insofar as there is no way to access the collective 'name' category without the services of anaphora, and thus any utterance containing an unmodified definite-fronted collective 'name' must possess elided content that ought to be syntactically represented. Often one can discern a dancer as a dancer perceptually (by seeing someone in performance, or making inferences based on dress) without hearing the fact from a communication chain with others, yet, one might argue, one cannot so discern a Katherine as a Katherine. One must hear about the Katherine from someone who has already identified her as someone named 'Katherine' or as someone who is a Katherine. Even leaving aside the complex issues whether referential reliance upon anaphora must be elliptical and demand hidden syntactic representation, this rationale is weak. For one, collective 'names' are not unique in this regard. The scope of reliance on anaphora for identifying reference with unmodified collective 'names' will be present for identifying reference with unmodified family 'names'. And many ordinary count nouns mark categories whose extension we can't discern by inspecting candidate objects. Although we cannot identify philosophers as such by inspection, all agree there are grammatical sentences containing 'the philosopher' sans hidden elided content.

Moreover, as our Festival example illustrates, it's easy to devise contexts involving categorization with a collective 'name' that is purely perceptual, bypassing anaphora and any name-containing linguistic communication chain. Our reporter identified the Persephone as a Persephone because she cottoned onto the color-coded dress, exactly in the way our Scottsman identifies a Stewart as a Stewart by his kilt's particular plaid.

In her (2015b), Fara offers what may appear to be a version of the Reinterpretation Strategy. There she acknowledged the fact that certain sentences containing 'the Kather- 
ine' unaccompanied by an overt restrictive modifier appear to be grammatical. Further, she noted, they appear to express content different from the corresponding sentence containing 'Katherine' in their stead. All of the examples she considers involve binding. Consider:

[26] In every race, the cat won.

[27] In every race, the Katherine won.

[28] In every race, Katherine won.

The truth of an utterance of [28] requires that a certain individual, Katherine, have been in every race and have won every race. The truth of [27], she claims, requires that in every race, the Katherine in that race won that race. [28] has exactly one truthmaker. [27] may have many, permiting a co-varying reading, just as does parallel construction [26]. [28] permits only a singular reading. Since 'the' and 'Katherine' in [27] are syntactic sisters, it appears in conflict with Where ' $\emptyset_{\text {the }}$ '.

Yet, according to Fara, [27] not only fails to contradict the rule; it provides indirect confirmation of it. To demonstrate the point, she proposes that [27], like [26], has hidden syntactic structure. Invoking Stanley and Szabo's idea that quantifier domain restriction is accounted for as nominal restriction (Stanley and Szabo 2000), she claims the actual syntactic forms are:

[29] In every race $x$, the cat $[$ in $x]$ won $[x]$.

[30] In every race $x$, the Katherine $[$ in $x]$ won $[x]$.

Because 'the Katherine' is followed by a restrictive modifier in [30], it fails to conflict with Where ' $\varnothing_{t h e}$ ', and thus, according to her, the reinterpretation demonstrates that her theory is not only not compromised by such sentences; they confirm it, because Where ' $\emptyset_{\text {the }}$ ' predicts such a resolution.

I agree that the co-varying reading of [27] can be explained by positing the syntactic form in [30], and thus will not conflict with Where ' $\emptyset_{t h e}$ '. However, [27] does not confirm the rule.

To see this, note that our referentialist analysis also predicts the same result vis-à-vis the co-varying reading of [27]. More precisely, on our account, if the correct analysis of [26] on its co-varying reading is given by [29], the correct analysis of [27] on its co-varying reading is [30]. This falls straightforwardly from the fact that collective 'names' are common count nouns.

But the true test cases concern sentences that do not easily receive co-varying readings, and for which the phrase 'every race' does not have the subject expression in its scope, as in:

[31] The cat won in every race.

[32] The Katherine won in every race.

[33] Katherine won in every race.

Here, [31] is most naturally interpreted as having a singular reading, expressing that a particular cat won every race, and is, in this respect, analogous to [28]. Fara claims that Where ' $\emptyset_{\text {the }}$ ' confirms her analysis precisely because it predicts that [32] is ungrammatical. Of a sentence like [32], she remarks 'Since the name is no longer in the scope of the variable binder, it does not have a variable-containing nominal restriction, and is therefore the syntactic sister of the definite article, which therefore, by my Where ' $\emptyset_{\text {the }}$ ' rule, must not be pronounced' (Fara 2015b, 7). 
The problem is that [32] is not ungrammatical. Watching a certain woman compete at a track meet, Colin could exclaim, perfectly grammatically:

[34] Wow, she's beautiful and fast. The Katherine won in every single race she entered!

Like our Party, Experiment, and Festival examples, [32] and [34] do not require reinterpretation and thereby disconfirm the Where ' $\emptyset_{\text {the }}$ ' rule. ${ }^{24}$ Overall, because the Reinterpretation Strategy requires positing additional syntactic structure to all The Katherine sentences, it remains ineffectual.

\section{\$6.2. The Novel-'The*'STRategy}

Let's consider The Novel-'the*' Strategy. Proponents of this strategy assent that there exist some grammatical The Katherine sentences. To preserve their Syntactic Rationale, they maintain that the null determiner that occurs directly before bare names is not the ordinary English definite 'the' that occurs with ordinary count nouns. It is, rather, a special determiner - 'the*' - that encodes a more fine-grained function for the definite. Proponents typically look to non-English languages that morphologically differentiate distinct functions or discourse roles of the definite, and posit that the null definite fronting bare names encodes that more fine-grained definite within English. For bare names, as in [1],

[1] Katherine wants coffee.

[5] $\emptyset_{\text {the }}$ Katherine wants coffee.

[35] $\varnothing_{\text {the }}{ }^{*}$ Katherine wants coffee.

instead of positing Null Determiner: 'the', [5], they posit Null-Determiner: Novel-'the*', [35].

One version of this strategy proposed by Fara draws on Daniel Rothschild's distinction between role-type and particularized definite descriptions. ${ }^{25}$ Role-type definite descriptions are used to indicate the unique occupant of a role, where the occupant shifts with metaphysically possible situations. For a canonical example, consider 'The mayor of Los Angeles'. On Rothschild's view, when it is common knowledge to conversational partners that there exists a unique satisfier, yet one that varies across situations, it may be used to designate whoever it is that occupies the role it expresses. Particularized definite descriptions are non-role-type. 'The kitten' is typically non-role type, used to indicate a particular kitten. Context determines whether a description is role-type or particularized. ${ }^{26}$ According to Rothschild, these two types differ syntactically and certain languages give them distinct morphological expression.

${ }^{24}$ Notice that like [31] and [32], [26] and [27] can also receive singular readings, in which case their form is represented thus:

In every race $x$, the cat won $[x]$.

In every race $x$, the Katherine won $[x]$.

25 (Rothschild 2007). Fara presented this route in her 2016 APA commentary on an ancestor of this paper.

26 If you are a regular pet shelter volunteer, temporarily adopting and weaning a new kitten each month, 'the kitten' can be used as a role-type description by one who knows your arrangement. 
To preserve the Syntactic Rationale, Fara suggested that The Katherine sentences are grammatical just in case the description is role-type. For her, then, Null Determiner: Novel 'the ${ }^{*}$ ' selects a determiner that is particularized, and thus what's excluded by the grammaticality of bare names is particularized uses of The Katherine sentences.

Aidan Gray advances a similar proposal which draws on a distinction between definite determiners which function to mark anaphora and others that mark the absence of anaphora. Noting that in some languages which distinguish these two types of definite determiners, the grammatical distinction is given morphological expression, he proposes that predicativists 'should hold that in English the overt definite article is unspecified with respect to the anaphoric/non-anaphoric distinction, but that the morphological rule which generates the bare occurrence is specified as applying only to non-anaphoric descriptions.' (Gray 2017, 31). On his account, The Katherine sentences would need for the definite to mark anaphora, as a contrast with the bare occurrence. Gray bolsters his account by drawing on examples like

[36] Two Ralphs and an Alfred came to the party last night. The Alfred was a famous semanticist.

[37] I'll find the Michael and the Helen, you find the Alfred.

where [37] presumes a context in which interlocutors know on purely general grounds that there is a unique Michael, Helen, and Alfred in their midst, yet know nothing about them beyond that. In [36], 'the Alfred' obviously involves anaphora on the previously introduced discourse referent 'an Alfred'. Gray claims that [37] does as well, adopting a broad construal of anaphora as a context in which 'the speaker and audience have no means, independent of the context, to identify the individuals in question'.

Fara and Gray's proposals both miss their mark. The paramount problem for Fara is that many of our The Katherine sentences transparently involve particularized definite descriptions. Colin asks about the location of a particular Katherine, the one he heard about from Hassan, and there's no presumption in the common ground that the description selects a role with a unique satisfier. The reporter aims to interview a particular Persephone amongst a gathering of Persephones, and 'The Persephone' cannot be regarded as characterizing a role that another could have occupied.

A corresponding problem arises for Gray. In two of our examples involving The $\mathrm{Ka}$ therine sentences, there's no reliance on anaphora at all, even in Gray's extremely broad sense. Prior to her assertion, the researcher has met and interacted with the Diego. We can even imagine he introduced himself to her by name. The festival reporter identifies the Persephone perceptually. In both, within the context, the speakers and audience possess multiple means of identifying and describing their intended referents and could even refer to them by name. Thus, even allowing for a very wide notion of anaphora, the speaker's use of the definite does not mark an anaphoric relation at all.

The felicitousness of The Katherine sentences is, in fact, in no way governed by specific features of the epistemic relation between speakers, hearers, and the intended referent. Thus, there's no reason to think a special definite is used to mark that relation. What dictates the felicitousness in all of our cases is simply the import of the collective 'name' category to the conversational partners and conversation at hand. Furthermore, the availability of reference by name-by a Katherine sentence-does not block or exclude reference with the collective 'name' count noun-by a The 
Katherine sentence. ${ }^{27}$ Hassan could simultaneously use 'the Katherine' to answer Colin and, in the same breath, refer to her to someone else, Ana, who has no Katherine hang-ups, as 'Katherine':

[38] Hey Colin, the Katherine is standing there in the corner. Ana, you made it. Katherine has been waiting for you.

Our researcher could use 'the Diego' to report her findings to colleagues, and moments later refer to him with 'Diego' to someone else.

A second problem arises for both proposals. By positing that the null determiner that occurs before bare names specifically encodes a novel definite 'the*', the-predicativists undercut their own syntactic motivation for positing the original Null Determiner: 'the' hypothesis. The-predicativist's justification for Null Determiner: 'the' concerned its necessity to preserve the common distribution between names and count nouns, showing that names differ trivially from other count nouns. The only difference concerned whether 'the' is pronounced in the bare unmodified singular. But now they are positing a highly non-trivial difference between names and common count nouns, maintaining that only with names does the definite mark a distinction between role-type and particularized/anaphoric and non-anaphoric definite descriptions, and, further, it does so only when the name occurs in the singular, bare and unmodified. ${ }^{28}$ Surely some specific syntactic data, independent of rescuing the ungrammaticality claim, would be needed to support the hypothesis on pain of its being ad hoc.

In sum, like The Reinterpretation Strategy, The Novel-'the *' Strategy cannot explain away our most central cases, and is, additionally, problematic for being unsupported by specific syntactic data. Both fail to safeguard the-predicativism from grammatical The Katherine sentences.

\section{Interlude}

What marked Sloat, Matushansky, and Fara's approach as distinctive was that a set of raw syntactic evidence appeared to forcefully favor the-predicativism over that-predicativism and referentialism. The presumed ungrammaticality of The Katherine sentences was crucial to their Parallel Syntax and Deviating Syntax theses, Fara's Where ' $\varnothing_{\text {the }}$ ' rule, and the Syntactic Rationale. All are undermined by the grammaticality of The Katherine sentences. Be-

27 Gray $(2017, \$ 5)$ claims that reference with 'Katherine' somehow blocks reference with 'the Katherine', but offers no data for thinking that one excludes the other. In fact, in all of my examples, the speaker could have chosen the name instead. The statement would have been felicitous though it would be different in content, and would therefore have diminished or excised the import of the collective name category within the conversation.

${ }^{28}$ Gray (2017, footnote 27) recognizes this problem, yet seems to me to minimize its significance. He remarks that positing a novel 'the*' is as arbitrary as positing null-'the' on standard the-predicativist analyses, with the morphological rule for why 'the' goes null applying exclusively to names. But the original Syntactic Rationale for the-Predicativism was principled, not arbitrary: Fara, Matushansky, and Sloat saw Null-Determiner-'the' as necessary to explain the syntactic data (as they saw it). Moreover, their claim that 'the' goes null before unmodified names didn't involve positing the existence of a new kind of determiner into English. 
cause their alleged ungrammaticality was the only data-point offered that, if true, would be incompatible with construing collective 'names' as common count nouns, their grammaticality instead corroborates so classifying them.

In $\$ \$ 2-3$, we supported Referentialism-Syntax by showing that names form ungrammatical constructions when directly preceded by: the indefinite article 'a', numerical determiners, quantifiers like 'some' and 'every', the deictic demonstrative 'that', the definite article 'the', and the definite article 'the' followed by a postnominal restrictive modifier. There I noted that the restricted interaction was difficult to establish in a theory-neutral fashion. We are in a different position now. Having shown The Katherine sentences to be grammatical when interpreted with a collective 'name' count noun, we now possess strong reason to recognize them as having different content from grammatical Katherine sentences, thereby undermining Univocity. Otherwise, we could not explain differences in their contextual felicitousness, in particular why the former, but not the latter, demand the salience of the category encoded in the collective 'name'. Initial sceptics about the data in $\$ \$ 2-3$ can now more easily appreciate it simply by holding fixed the differential content between names and collective 'name' count nouns while making grammaticality judgments about their patterning with determiners.

Sloat, Matushansky, and Fara all claimed that, save for a select class of modified bare names and the covertness of 'the' before bare names, names pattern with determiners just like common count nouns. This, we've seen, is incorrect. In the following six sections, I showcase a far broader set of syntactic data that demonstrates that while names do interact with some determiners and modifiers, their interaction pattern sharply diverges from that of count nouns. To deepen the case for Referentialism-Syntax and Referentialism-Semantics, I examine names' and count nouns' interaction with demonstratives, \$8; possessives, $\S 9$; pure expressives, $\$ 10$; bare modifiers, $\$ 11$; and determiner fronted pre- and post-nominal modifiers, $\$ \$ 12,13$.

\section{Deictic, anaphoric, and affective demonstratives}

The demonstrative expressions 'that' and 'this' have at least three functions. ${ }^{29}$ First, when combined with singular count nouns, 'that' and 'this' may function as deictic demonstratives. In these uses as spatio-temporal indicators, they are often accompanied by extra-linguistic contextual supplementation, typically gestures. Consider:

[39] This cat wants water.

The speaker may use 'this' in [39] contrastively, to indicate which cat, among a number of other cats, is intended. Yet contrastive use is not necessary. The speaker may use [39] purely deictically, for instance when she believes there are no other cats around.

Second, demonstratives have an anaphoric use, to indicate an individual previously attended to or referenced in an earlier (or earlier stage of) discourse. Suppose a man dropped by last week, a matter you then discussed with your roommate. After a visit today, you say to her:

[40] That man stopped by.

${ }^{29}$ Lakoff (1974) discusses all three uses. 
Here, 'that' is used to indicate a referent previously encountered or discussed.

Third, 'that' and 'this' function as affective demonstratives, a phenomenon first analyzed by Lakoff. On her view, affective demonstratives are employed as 'markers of solidarity, indicating the speaker's desire to involve the listener emotionally and foster a sense of closeness and shared sentiment' (Potts and Schwarz 2010, 2). Consider:

[41] How is that toe feeling?

[42] That cat is such a sweetie!

[43] There was this traveling salesman, and he...
[Acton and Potts example]

[Lakoff example]

For each sentence, 'that' and 'this' are neither being employed deictically nor anaphorically. A doctor might use [41] to refer to the hearer's splinted toe, the referent apparent and mutually known to be so by speaker and hearer prior to the utterance. Similarly, [42] could be used when there is no question over which is the intended cat-it may be the lone cat on the scene. Although both may involve communications about referents likely subjects of previous discourses (as in [41]), the background conditions for anaphoric demonstratives are missing in [43]. There the speaker is telling a story, not referring to a perceived or previously discussed salesman, and introduces a new discourse referent with 'this' rather than the indefinite ' $a$ ' in order to 'involve the addressee more fully'. 3031

My claim: count nouns directly preceded by 'that' and 'this' take deictic, anaphoric, and affective demonstratives; names take only affective demonstratives. ${ }^{32}$ The following chart provides evidence, contrasting the patterning of collective, family, and brand 'names' on the left with that of names on the right. For the deictic demonstratives examples, assume an accompanied pointing; for anaphoric examples, assume contexts that background a previous discourse about the referent. ${ }^{33}$

\section{Deictic demonstratives}

\begin{tabular}{|l|l|}
\hline \multicolumn{1}{|c|}{ Count Nouns } & \multicolumn{1}{c|}{ Names } \\
\hline That Katherine wants coffee. & *The children hugged that Katherine. \\
That Leica is damaged. & *That Tesla promises to sell an affordable car in 2018. \\
\hline
\end{tabular}

30 See Lakoff (1974, 347). Cf., also Wolter (2006), Potts and Schwarz (2010), Acton and Potts (2014), and Language Log, http://languagelog.ldc.upenn.edu/nll/?p=674

${ }^{31}$ Demonstratives may sometimes do double-duty, indicating spatio-temporally while generating affect. While interesting questions exist regarding what sort of affect is encoded, how it is encoded, and whether it is directed toward the hearer or the object referenced by the noun, we need not settle them to establish our syntactic points.

32 Lyons $(1999,122)$ and Ghomeshi and Massam $(2005,7)$ concur that count nouns take both deictic and affective demonstratives, yet names are only grammatical with affective demonstratives.

33 'That Donald Trump is really something!' is modeled on Lakoffs Henry Kissinger example. 
Anaphoric demonstratives

\begin{tabular}{|l|l|}
\hline \multicolumn{1}{|c|}{ Count Nouns } & \multicolumn{1}{c|}{ Names } \\
\hline That Katherine stopped by. & *That Katherine finally called you. \\
Have you run into that Corleone again? & *Have you heard what that Donald Trump said? \\
\hline
\end{tabular}

Affective demonstratives

\begin{tabular}{|l|l|}
\hline \multicolumn{1}{|c|}{ Count Nouns } & \multicolumn{1}{c|}{ Names } \\
\hline $\begin{array}{l}\text { I don't know what to do to get that Katherine } \\
\text { to love me. }\end{array}$ & That Katherine sure does love you. \\
$\begin{array}{l}\text { There was this Corleone, the most dangerous } \\
\text { of all... }\end{array}$ & That Donald Trump is really something! \\
$\begin{array}{l}\text { It's a beauty! Make sure you get a sturdy strap } \\
\text { for that Leica. }\end{array}$ & $\begin{array}{l}\text { I know you think no company innovates boldly, } \\
\text { but this Tesla sure looks to be an outlier. }\end{array}$ \\
\hline
\end{tabular}

In offering a dual distribution, referentialism explains this data and can offer a plausible explanation of why names do not take deictic or anaphoric demonstratives: the name already, by itself, provides the referent, making superfluous the deictic and anaphoric demonstratives' noun-modifying function. Names do combine with affective demonstratives because in such constructions 'that' only contributes to injecting affect into the context, not reference determination. Predicativists must deny at least part of this data set: their single class of name count nouns cannot simultaneously be grammatical and ungrammatical with deictic and anaphoric demonstratives.

\section{Possessive pronouns and affective possessive pronouns}

Like demonstratives, possessive pronouns exhibit differential behavior in how they interact with count nouns and names. Possessives (including 'my', 'our', 'your', 'his', 'her') standardly have a dual status, capable of functioning simultaneously as both determiners and attributives. This is exhibited in their combination with count nouns: in the sentences on the left, 'my' and 'our' manifest both functions by restricting the extension of the count nouns with their encoded attributes. When combined with count nouns, the speaker does not express or implying any affective states.

Possessive pronouns

\begin{tabular}{|l|l|}
\hline \multicolumn{1}{|c|}{ Count Nouns } & \multicolumn{1}{|c|}{ Names } \\
\hline $\begin{array}{l}\text { My daughter surprised us with an impromptu } \\
\text { visit home. }\end{array}$ & $\begin{array}{l}\text { My Katherine surprised us with an impromptu } \\
\text { visit home. }\end{array}$ \\
When will our dog need his next vaccine? & When will our Rover need his next vaccine? \\
\hline
\end{tabular}


By contrast, when possessive pronouns are combined with names, they coerce a speakeroriented affective interpretation, often expressing the speaker's attitude toward the name's referent.

As with demonstratives, referentialism can accommodate the differential behavior and explain it: because names semantically determine their specific referents, when preceded by a possessive, the determiner-function of the possessive is coerced to perform a distinct nonrestrictive lexical function-an expressive function. While possessives still attribute properties to the referent, their attributive function is detached from their standard determiner function. The-predicativism needs to collapse or otherwise deny the dual distribution for collective 'names' and proper names.

\section{Pure expressives}

English contains a spate of words - 'goddamn', 'fucking', 'effin', 'freak'n' —often dubbed pure expressives or expressive attributive adjectives. ${ }^{34}$ They are important for our investigation because although they are syntactically similar to strictly attributive adjectives ('the former minister', 'the main thesis') ${ }^{35}$, qua pure expressives, their lexical contribution is always speaker-oriented and independent of at-issue content. ${ }^{36}$ So while they are syntactically modifiers, they never function as restrictive modifiers, which, we'll see, compounds problems for the Where ' $\varnothing_{\text {the }}$ 'rule.

Pure expressives

\begin{tabular}{|c|c|}
\hline Count Nouns & Names \\
\hline *Why is goddamn billionaire our president? & Why is goddamn Donald Trump our president? \\
\hline *Freak'n dog barked all night. & Freak'n Rover barked all night. \\
\hline $\begin{array}{l}{ }^{*} \text { I smiled at her, but goddamn Katherine looked } \\
\text { away. }\end{array}$ & $\begin{array}{l}\text { I smiled at her, but goddamn Katherine looked } \\
\text { away. }\end{array}$ \\
\hline Why is the goddamn billionaire our president? & $\begin{array}{l}\text { *Why is the goddamn Donald Trump our presi- } \\
\text { dent? }\end{array}$ \\
\hline The freak'n dog barked all night. & *The freak'n Rover barked all night. \\
\hline $\begin{array}{l}\text { I smiled at her, but the goddamn Katherine } \\
\text { looked away. }\end{array}$ & $\begin{array}{l}\text { *I smiled at her, but the goddamn Katherine } \\
\text { looked away. }\end{array}$ \\
\hline
\end{tabular}

34 See Potts (2005), Soames (2002), Huddleston and Pullum (2002).

35 Strictly attributive adjectives do not function as predicates. Ordinary attributive adjectives ('tall') function to both qualify the noun they precede and as predicates: 'The tall man arrived' and 'The girl is tall'. Strictly attributive adjectives are restricted to attributive function: ${ }^{*}$ The minister is former'. In this respect, pure expressives track their syntactic properties: *'The dog is goddamn'.

36 A slight over-simplification: in my view, they can fail to be speaker-oriented in indirect belief reports and free indirect discourse. This qualification does not impact the points here. Cf., Potts (2005) for a dissenting view on indirect belief reports, Schlenker (2007) for a view similar to my own. 
Names and count nouns combine with pure expressives differently. Names may be directly preceded by pure expressives in the absence of any determiner and are ungrammatical when the expressive is directly preceded by 'the'. Common nouns, including collective, brand, and family 'names', exhibit the opposite behavior.

Again, referentialism explains the differences by positing the dual distribution. Predicativism must deny some of data so as to assign a single set of grammaticality judgments for their special category of name count nouns. ${ }^{37}$

A related problem is that some of this data conflicts with Fara's Where ' $\emptyset_{t}$ ' ' rule. In the upper right quadrant, 'Donald Trump', 'Rover', and 'Katherine' are all preceded by modifiers that are not themselves preceded by the overt definite 'the', but the sentences are grammatical. To account for this, two routes appear open. One is to maintain that pure expressives are not modifiers. Yet this is unattractive. At the syntactic level, pure expressives are just left-adjoined modifiers, a point emphasized by Potts (2005, ch. 5). An alternative is to regard the pure expressives in such sentences as special cases, perhaps akin to the way Fara construes bare pre-name modifiers like 'poor' in 'Poor Lenny lost his dog' which, she recognizes, also conflict with Where ' $\varnothing_{\text {the }}$ '. I turn my attention to such constructions now and show that it is misguided to cordon them off as curious exceptions to Where ' $\emptyset_{t h e}$ '. In fact, pure expressives help illuminate why names do combine with bare modifiers-precisely because they never function restrictively. Together, the two classes of pre-name modifiers reveal that Where ' $\emptyset_{\text {the }}$ ' is false because it merges syntactic data about names and collective 'name' count nouns.

\section{Bare pre-name and pre-count noun modifiers}

The most complicated syntactic phenomena concern how names and count nouns interact with modifiers. In this section, I discuss bare modifiers, modifiers that are themselves not directly preceded by a determiner.

One set of data demanding explanation is clear-cut. Names combine with bare modifiers. Singular count nouns, including collective 'names', do not. ${ }^{38}$ More precisely, certain modifiers may occur bare directly fronting names and these same modifiers do not so combine with singular count nouns.

${ }^{37}$ Matushansky (2006, footnote 9) claims that pure expressives require an affective demonstrative. This is wrong, as exemplified in the chart. What's right is that pure expressives may occur between an affective demonstrative and both name and common count noun - 'that freak'n Donald Trump', 'that freak'n billionaire'. But the test for the-predicativism is whether there exist differences in how names and count nouns interact with pure expressives, some of which are presented above.

38 The sentence with 'Éamonn McManus' is in Pullum (2006). The sentences with 'Katherine' are based on an example in Fara (2015a). 


\section{Bare modifiers}

\begin{tabular}{|c|c|}
\hline Count Nouns & Names \\
\hline *They all sigh and want to die for sweet girl. & $\begin{array}{l}\text { They all sigh and want to die for sweet Geor- } \\
\text { gia Brown. }\end{array}$ \\
\hline $\begin{array}{l}{ }^{*} \text { Good old man entertained the children for } \\
\text { hours. }\end{array}$ & $\begin{array}{l}\text { Good old Jack entertained the children for } \\
\text { hours. }\end{array}$ \\
\hline *That crazy cat swatted at poor dog. & That crazy cat swatted at poor Rover. \\
\hline $\begin{array}{l}\text { *Sharp-eyed reader noticed the mistake right } \\
\text { away. }\end{array}$ & $\begin{array}{l}\text { Sharp-eyed Éamonn McManus noticed the } \\
\text { mistake right away. }\end{array}$ \\
\hline $\begin{array}{l}\text { *Young Katherine would be happy to stay } \\
\text { young forever. }\end{array}$ & $\begin{array}{l}\text { Young Katherine would be happy to stay young } \\
\text { forever. }\end{array}$ \\
\hline
\end{tabular}

An adequate theory also needs to explain why only some modifiers can occur bare before names. We are faced with a curious phenomenon: 'Sweet' is an acceptable pre-name modifier while 'sweeter' is impossible. 'Poor' is fine yet canonical synonyms- 'destitute', 'impoverished' - are unavailable. Which modifiers cannot be bare pre-name modifiers? The question is an interesting one and, while I cannot advance a full answer here, a sufficient condition will serve our purposes: any modifier that requires a restrictive interpretation, like comparative and superlative adjectives, cannot occur bare before names.

[44] *They all sigh and want to die for sweeter Georgia Brown.

[45] *Youngest Katherine would be happy to stay young forever.

[46] *Sharper-eyed Éamonn McManus noticed the mistake right away.

Referentialism offers a compelling analysis of both the dual distribution pattern and why only some modifiers can function as bare pre-name modifiers: because they are modifying names, bare pre-name modifiers must be non-restrictive. The account tallies with our prior accounts of affective demonstratives, possessives, and pure expressives.

Before advancing the analysis, let us first distinguish examples like 'poor Rover' and 'good old Jack' in which the modifier makes a lexical contribution independent of the name from examples in which the modifier and the name become a single composite, ${ }^{39}$ as in: 'Shoeless Joe Jackson', 'Mama Cass', 'Air Jordan'. Here, 'shoeless', 'mama', and 'air' make no lexical contribution independent of the name. Deleting them from the sentence alters the name itself, though not its referent. By contrast, in our examples of bare pre-name modifiers, the modifier has not merged with the name to form a new name and does make its own lexical contribution.

I maintain that for many bare pre-name modifiers as in our first three examples, the modifier's function is primarily expressive, encoding the speaker's attitudes toward the

39 Such name-creation is similar to descriptions that 'grow capitals' as when 'The Queen of Soul' becomes a name for Aretha Franklin. 
name's referent, while making no independent contribution to truth-conditional content. With 'sweet', the speaker primarily reveals her affection toward Georgia Brown; with 'good old', her warm sentiment toward Jack; with 'poor', her empathy toward Rover. ${ }^{40}$ While non-restrictive, they are not merely non-restrictive: their dominant function is expressive, not descriptive.

This analysis accounts for why modifiers with lexically overt restrictive meaning like 'sweeter' and 'youngest' cannot function as pre-name modifiers. It also shows why other modifiers difficult to interpret as at least partially revealing the speaker's attitudes are unlikely candidates as bare pre-name modifiers. ${ }^{41}$ Although 'poor', when it functions restrictively, has as rough synonyms 'destitute' and 'impoverished', because they lack expressive lexical functions, neither is a natural bare pre-name modifier. Accordingly, bare pre-name modifiers' expressive function delimits which modifiers can be bare modifiers. Further support derives from the fact that those bare pre-name modifiers whose lexical contributions are not exclusively speaker-oriented—as in 'young Katherine' and 'sharp-eyed Éamonn McManus' - also take on an auxiliary expressive function. One naturally interprets those sentences as not only attributing youth to Katherine, perceptiveness to McManus, but also as encoding the speaker's (pro-) attitudes toward them.

I propose that many bare pre-name modifiers only contribute an expressive content independent of truth-conditional content ('good old', 'poor'), akin to that of pure expressives. Others ('sharp-eyed', 'young') have an additional lexical function to attribute a property to the name's referent, yet they never function restrictively. Both are referentialistfriendly analyses.

Furthermore, referentialism explains why bare pre-name modifiers must occur non-restrictively: because names themselves determine their referents, they resist restrictive modification. Alternatively put, when modifiers occur bare before names, they are either coerced to function non-restrictively or become ungrammatical.

On each count, predicativism struggles. First, the-predicativism is incompatible with the dual distribution for collective 'name' count nouns and names: it cannot countenance both the ungrammaticality and grammaticality of 'Young Katherine would be happy to stay young forever'.

Second, while Sloat, Matushansky, and Fara all acknowledge that bare pre-name modifiers must occur non-restrictively, none offer an explanation why. Third, bare pre-name modifiers constitute another set of counterexamples to the $W$ here: ' $\varnothing_{\text {the }}$ ' rule. Recognizing this, Fara moves to cordon them off as strange exceptions on the grounds that every modifier that can occur bare before (what she regards as) name count nouns can also occur with them non-bare, fronted by a definite, but not vice versa. The idea seems to be that the class of modifiers constituting exceptions is comparatively small. ${ }^{42}$ The suggestion is unsatisfying: it fails to illuminate why these modifiers, in contrast with others, do not observe the (alleged) obligatory contraction; and it fails to explain why bare pre-name modifiers cannot

40 All are also susceptible to ironic readings.

${ }^{41}$ Certain apparently lexically restrictive modifiers can front names as bare modifiers, but when they do so, they never function restrictively. One can exclaim 'Sweetest Georgia Brown finally came home!' but 'sweetest' here functions to intensify the force of the expressive, not to restrict the name.

${ }^{42}$ Cf. Fara’s discussion (2015a, especially $\$ \$ 9-10$ ). Matushansky (2006) cordons off bare pre-name modifiers as exceptional because, she maintains, English, French, and Dutch exhibit different behavior. 
be restrictive. Our analysis does both, revealing that bare modifiers' appearance as exceptions results from merging the distribution of collective 'name' count nouns with that of names, which resist restrictive modification.

\section{Pre-name modifiers preceded by definites and indefinites}

Let's now examine how names and count nouns interact with modifiers that are themselves preceded by definites and indefinites. I call these determiner-fronted modifiers and divide them into definite-fronted modifiers and indefinite fronted-modifiers. Determiner-fronted modifiers interact with names and count nouns differently. Count nouns, including collective 'names', freely interact with determiner-fronted modifiers. In particular, modifiers that can function restrictively in fact restrict the extension of the count noun and there are no special systematic lexical effects induced when alternately combined with definites and indefinites. By contrast, when names are combined with determiner-fronted modifiers, the modifiers never function restrictively. They only attribute a property to the name's referent. Consequently, there exist systematic coerced shifts in meaning correlated with whether the pre-name modifier is fronted by a definite or indefinite. Additional coerced meaning shifts occur when names are combined with lexically restrictive modifiers.

The left side of the table exhibits examples of count nouns preceded by definite- and indefinite- fronted modifiers. Each sentence admits an interpretation on which the modifier restricts the count noun, including the one containing the collective 'name' count noun. 'Rambunctious' can restrict the count noun 'Katherine' when it occurs as both definite and indefinite-fronted modifier, just as 'left-footed' can restrict 'striker' in both constructions.

\section{Determiner-fronted modifiers: Contrast between definites and indefinites}

\begin{tabular}{|l|l|}
\hline \multicolumn{1}{|c|}{ Count Nouns } & \multicolumn{1}{|c|}{ Names } \\
\hline $\begin{array}{l}\text { The left-footed striker dominated play for Barça. } \\
\text { A left-footed striker dominated play for Barça. }\end{array}$ & $\begin{array}{l}\text { The left-footed Messi dominated play for Barça. } \\
\text { A left-footed Messi dominated play for Barça. } \\
\text { The exhausted soldier wept outside the church. } \\
\text { An exhausted soldier wept outside the church. }\end{array}$ \\
$\begin{array}{l}\text { Our team desperately needs the explosive mid- } \\
\text { fielder. }\end{array}$ & $\begin{array}{l}\text { Thexhausted Obama exited Air Force One. } \\
\text { Our team desperately needs an explosive mid- } \\
\text { fielder. }\end{array}$ \\
$\begin{array}{l}\text { Our team desperately needs the explosive Carli } \\
\text { Colin stared at the rambunctious Katherine. } \\
\text { Colin stared at a rambunctious Katherine. }\end{array}$ & $\begin{array}{l}\text { Our team desperately needs an explosive Carli } \\
\text { Colin stared at the rambunctious Katherine. } \\
\text { Colin stared at a rambunctious Katherine. }\end{array}$ \\
\hline
\end{tabular}

Now consider the right side containing names. When names are combined with the same determiner-fronted modifiers, they cannot function restrictively. 'Left-footed' can only 
attribute a property to Messi, 'explosive' a property to Lloyd, 'exhausted' a property to Obama. Thus the logical form of the definite- and indefinite-modifier containing sentence pairs will be the same. Accordingly, the choice of the definite or indefinite gives rise to implicated non-truth-conditional content. One systematic effect is illustrated: indefinite fronted pre-name modifiers indicate that the attributed property is temporary, while definite fronted pre-name modifiers suggest that it is an enduring, typical, or standing property of the name's referent. ${ }^{43}$ The effects are illustrated in the contrast between our pairs. A natural response to 'A left footed Messi dominated play for Barça' is "What do you mean "a"? Messi has always been left-footed!'; to the Obama sentence, "What do you mean "the"? Obama is normally fairly energetic.' The choice of the definite for the Lloyd sentence implicates that the team needs Lloyd, the famously explosive soccer star, while the indefinite implicates that the team needs Lloyd to be explosive during a certain time period or for a certain event (today or for this game). ${ }^{44}$ No such effects are generated in our corresponding count noun pairs.

Similar patterns obtain for count nouns and names preceded by lexically restrictive modifiers like comparative and superlative adjectives. Count nouns combine with such modifiers freely, receiving the standard restrictive interpretation. When names combine with such modifiers, however, they cannot restrict the extension of the name, and invariably induce meaning shifts. For instance, with 'younger' and 'other' modifying name occurrences of 'Obama', the subject shifts to some earlier time slice of Obama.

\section{Determiner-fronted modifiers: Lexically restrictive modifiers}

\begin{tabular}{|l|l|}
\hline \multicolumn{1}{|c|}{ Count Nouns } & \multicolumn{1}{c|}{ Names } \\
\hline $\begin{array}{l}\text { Would a younger child be able to play that cello } \\
\text { suite? }\end{array}$ & $\begin{array}{l}\text { Would a younger Obama vote for military ac- } \\
\text { tion? }\end{array}$ \\
Tell me about the other Francis Bacon. & $\begin{array}{l}\text { The youthful idealism from his community-or- } \\
\text { ganizing days resounds with many Chicagoans. } \\
\text { They prefer the other Obama. }\end{array}$ \\
\hline
\end{tabular}

43 The implicated content regarding temporary and enduring properties is importantly related to distributional effects due to what linguists call 'stage-level' and 'individual-level' predicates. For instance, 'There are firemen available' is grammatical while 'There are firemen altruistic' is not, which is explained by the fact that the former predicate is stage-level, the latter individual-level. The examples and seminal work on the phenomena are due to Carlson (1977).

44 The lexical effects also receive support from examples requiring a semantic shift. Consider:

Dudamel conducted the/a spectacular Carmina Burana at the Hollywood Bowl.

Dudamel conducted the/a spectacular cantata at the Hollywood Bowl.

The definite-fronted modifier of the name signals that being spectacular is an enduring property of Carmina Burana, leaving the standard interpretation of the name available. Because the indefinitefronted modifier signals a temporary property and a musical work cannot temporarily be spectacular, the indefinite coerces a semantic shift. 'Spectacular' now modifies a count noun: Dudamel conducted a spectacular performance of Carmina Burana. With the corresponding count noun 'cantata', no such effect is on display. 
As we've seen previously, our theory can explain the dual distribution and additionally explain why names induce these special effects. Predicativism must implausibly collapse the data to accommodate a single distribution for their class of name count nouns.

\section{Post-nominal modifiers}

Finally, with respect to post-nominal modifiers, essentially the same phenomenon is reduplicated. Count nouns combine with both non-restrictive and restrictive post-nominal modifiers. Names combine only with the former. Non-restrictive modifiers are exemplified in the first set, restrictive in the second.

Post-nominal modifiers

\begin{tabular}{|l|l|}
\hline \multicolumn{1}{|c|}{ Count Nouns } & \multicolumn{1}{c|}{ Names } \\
\hline $\begin{array}{l}\text { The Leica, which cost a pretty-penny to fix last } \\
\text { time, needs repairs once again. }\end{array}$ & $\begin{array}{l}\text { Obama, who campaigned expertly, needs to re- } \\
\text { vitalize the peace-treaty. }\end{array}$ \\
$\begin{array}{l}\text { The Katherine, who normally runs only the } \\
\text { mile, won in every single race today. }\end{array}$ & $\begin{array}{l}\text { Katherine, who normally runs only the mile, } \\
\text { won in every single race today. }\end{array}$ \\
\hline $\begin{array}{l}\text { The Tesla that we drove to Yosemite sailed } \\
\text { over the mountain pass. }\end{array}$ & $\begin{array}{l}\text { *Obama who campaigned expertly needs to re- } \\
\text { vitalize the peace-treaty. }\end{array}$ \\
I smiled at the Katherine who runs the mile. & *I smiled at Katherine who runs the mile. \\
\hline
\end{tabular}

This data reinforces our claim that the-predicativists have bypassed important syntactic facts. For restrictive modifiers, Sloat and Fara specify only patterns for collective 'name' count nouns, leaving out the ungrammaticality of names with post-nominal restrictive modifiers, as in 'Obama who campaigned expertly needs to revitalize the peace treaty'. And 'The Katherine, who normally runs only the mile, won in every single race today' offers another counterexample to Fara's Where ' $\varnothing_{\text {the }}$ ' rule. As with our previous data sets, predicativism cannot countenance the distinctive patterning of names and collective 'name' count nouns with post-nominal modifiers. Referentialism accommodates it, and by construing names as determining their referents, explains the ungrammaticality of their combination with post-nominal restrictive modifiers. ${ }^{45}$

45 When names do occur with restrictive post-nominal modifiers and are preceded by a determiner, meaning-shifts are induced, as in the googled example 'While the Venice of yesteryear is gone, the legacy remains.' 


\section{Conclusion}

Let us take stock. We have seen a substantial set of novel data exhibiting names' and count nouns' differential distribution with demonstratives, possessives, bare expressives, and a range of modifiers. Taken together with that in $\$ \$ 2-3$, it contributes to demonstrating Referentialism-Syntax, that names' interaction with the determiner system is limited and in a fashion straightforwardly explained by Referentialism - Semantics, by the fact that names themselves determine their referents. $\$ \$ 8-13$ demonstrate that names systematically resist determiners and modifiers that must function restrictively. Names resist deictic and anaphoric demonstratives, the determiner function of possessive pronouns, lexically restrictive bare modifiers, and restrictive post-nominal modifiers. Their resistance to restriction is manifest by the fact that when demonstratives and possessives do combine with names, they inject affect into the conversational context and content. Similarly, names accept pure expressives and certain bare modifiers precisely because their semantic contribution is limited to expressive and attributive functions, never restrictive. Determiner-fronted modifiers reinforce names' resistance to restriction: when combined with names, definites and indefinites are coerced to imply that the attributed properties are standing or temporary, respectively. Our analysis traded upon contrasting names' resistance to restriction with count nouns', including collective 'name' count nouns', acceptance of it. We saw that for every determiner and modifier combination, collective 'names', like brand and family 'names', exhibit the same distribution with the determiner system as other count nouns, including in their interaction with the definite. The data overwhelmingly demonstrates that names are referential expressions, collective 'names' are count nouns, and the two cannot be assimilated into a single syntactic class.

Our case on behalf of Referentialism-Syntax is simultaneously a case against predicativism. This follows from our dual syntactic distributions, one for names, one for collective 'name' count nouns, typically at odds, for predicativists cannot countenance grammaticality and ungrammaticality at once. Also amongst the data are four different types of grammatical sentences constituting counterexamples to Where ' $\varnothing_{\text {the }}$ ', Fara's rule that is supposed to explain why 'the' sometimes occurs covertly. Recall:

Where ' $\varnothing_{\text {the }}$ ': The definite article will appear as null before names, except when it is heavily stressed or when the names are preceded by modifiers or followed by restrictive modifiers.

\section{Counterexamples:}

Singular unmodified collective 'name' preceded by 'the' (The Katherine sentences):

Where is the Katherine?

Singular collective 'name' preceded by 'the' followed by non-restrictive modifier:

The Katherine, who normally runs only the mile, ran in every single race today.

Name preceded by pure expressive:

Why is goddamn Donald Trump our President?

Name preceded by bare modifier:

The crazy cat swatted at poor Rover.

Notable amongst our data are grammatical The Katherine sentences for they directly conflict with what the-predicativists champion in the Syntactic Rationale and erroneously take 
to be semantically equivalent to Katherine sentences. They are, to be sure, important, deserving of being featured in my title, and definitely fun. It would be easy for them to overshadow the overarching argument, easy for readers to abridge its message as a case for their grammaticality. ${ }^{46}$ But the argument is rather that there exists a robust set of wide-ranging syntactic data that is, as a set, accurately, coherently, and wholly accounted for by countenancing collective 'names' as count nouns and names as referential expressions whose specific pattern of interaction with determiners and modifiers is itself predicted and explained by their being referential.

Before closing, I wish to highlight my argument's novelty and power by contrasting it with an alternative style of response to Matushansky and Fara by fellow-referentialists, Gail Leckie and Anders Schoubye. While substantial differences exist, Leckie's polysemy and Schoubye's type-ambiguity views share a fundamental feature with mine. On all our views, an expression like 'Katherine' sometimes has an individual as its semantic value and sometimes has a predicate-type value meaning individual named 'Katherine'. But our arguments employ different strategies. Leckie and Schoubye's primary arguments both conform to what I call a semantic alternative strategy. Each begins their argument by acceptance of the syntactic data presented by predicativists, taking it at face value and as a dialectical starting point, and neither advances any alternative syntactic data requiring explanation. Schoubye, but not Leckie, assents to the-predicativist's claims about names' special interactions with the definite. ${ }^{47}$ From there, each proceeds to advocate an alternative analysis, mounting a defense to demonstrate how their respective versions of referentialism are as explanatory, unifying, and theoretically parsimonious with respect to that data as the-predicativism. While each advance important subsidiary reasons for regarding their positive analyses as superior to the-predicativism, ${ }^{48}$ my focus here is just on con-

${ }^{46}$ For this reason, it is dialectically misguided for predicativists to focus exclusively on explaining away grammatical The Katherine sentences. This appears to be Gray's primary strategy in his (2017), which admirably wrestles with the syntactic issues revolving around 'the' and results in the promotion of a new version of predicativism. On Gray's position, idiosyncratic predicativism, the definite that fronts bare names is not the ordinary definite 'the', but a novel definite 'the"' marked as non-anaphoric (See \$6). Leaving aside the difficulties with this posit, any version of predicativism still needs to account for names' and count nouns' differential interaction with the indefinite, numerical determiners, quantifiers, demonstratives, possessives, pure expressives, bare modifiers, and determiner fronted preand post-nominal modifiers. And there is more syntactic data recently explored by others. Junhyo Lee (2018) offers striking disparities involving name/noun incorporation and modification.

47 Leckie (2013) does not address the matter.

48 After arguing that her polysemy view is as explanatory as predicativism, Leckie finds fault with predicativism because (i) the property of being called 'Katherine' is, she says, abstruse, so there is reason to think it isn't activated when expressions like 'Katherine' occur in argument position; and (ii) it makes name-learning an implausibly intellectualist affair by requiring the mastery of meta-semantic concepts. While both considerations are, in my view, forceful, I worry whether predicativists will feel much pressure from them.

Schoubye's initial argument is that his account is on a par with predicativism in its unificatory power and capacity to explain inferential relations between the two types of names. He then argues that predicativism is weaker insofar as it has difficulties securing rigidity when names are referential. I find persuasive much of his argumentation concerning rigidity and believe it puts considerable pressure on predicativism. 
trasting my argument with their primary dialectical strategy, one that Leckie aptly describes as a 'counter' to predicativism. ${ }^{49}$

While the strategy has inspired promising semantic theories of names, this dialectical starting point is too concessive to predicativism. By allowing the predicativist data-set to be agenda-setting, determining all and only that which ought to be explained, proponents advance a far less powerful case against predicativism than is available. For anyone who posits a class of referential names and a class of predicative 'names', the question arises: what is the syntactic distribution of each of these classes? Answering this question, we have seen, provides a wealth of syntactic data that undermines rather than evens the score with predicativism. Correspondingly, while the semantic alternative strategy aims to counter predicativists' uniformity argument, in bypassing assessment of the syntactic data, it leaves referentialist proposals vulnerable to the Syntactic Rationale which champions the-predicativism's theoretical superiority in explaining names' (alleged) anomalous distribution with 'the', particularly those taking as data the ungrammaticality of The Katherine sentences. By contrast, our argument undercuts the very data upon which the Syntactic Rationale for Predicativism rests.

There is another way in which Schoubye concedes too much to predicativism, one that has implications for his semantics of referential names. Consider the following arguments. In Argument 1, we have a premise containing a name and a conclusion containing a collective 'name' count noun; in Argument 2, the reverse:

\section{Argument 1}

$\underline{\text { Katherine wants coffee. }}$

Therefore, at least one Katherine wants coffee.

\section{Argument 2}

No Katherine wants coffee.

There exists at least one Katherine.

Therefore, Katherine does not want coffee.

Various predicativists maintain that arguments such as these are intuitively valid, a fact best explained by acknowledging a semantic connection between premises and conclusion. ${ }^{50}$ Schoubye (2017) agrees, claiming such inferential relations 'ideally should be explained in terms of the semantics,' a commitment that inspires him to construe the semantics of names on analogy with pronouns. ${ }^{51}$

Affirming the superiority of a semantic explanation for these arguments' intuitive validity concedes too much. To explain these inferential connections, we need not link the

49 Fara $(2015 \mathrm{a}, 110)$ praises this strategy as the best option for referentialists.

50 Some predicativists have even claimed that in the absence of a semantic connection, the intuitive validity of the inferences would be inexplicable' (Sawyer 2010, 207).

51 I find Schoubye's construing names on analogy with pronouns interesting but unconvincing. He maintains that pronouns like names have both referential and predicative occurrences, citing sentences like 'The cat is a she' as an instance of the latter. Yet pronouns' syntactic distribution in their referential occurrences varies from that of names; and their distribution in predicative occurrences varies dramatically from that of count nouns. A summary of the syntactic distribution for some determiners considered in $\$ \$ 2,3$ : 
semantics of names with the semantics of the collective 'name' count noun and there is no reason to regard a semantic account superior. The first argument is valid because if it is true that Katherine wants coffee, then, because Katherine is a Katherine, at least one Katherine wants coffee. We recognize the argument as intuitively valid because anyone compe-

\begin{tabular}{|c|c|c|c|}
\hline${ }^{*}$ A she wants water. & ${ }^{*}$ A Katherine wants coffee. & $\begin{array}{l}\text { We adopted a she. } \\
\text { A she wants water. ?? }\end{array}$ & A Katherine wants coffee. \\
\hline${ }^{*}$ Two shes want water. & $\begin{array}{l}{ }^{*} \text { Two Katherines want } \\
\text { coffee. }\end{array}$ & $\begin{array}{l}\text { We adopted two shes. } \\
\text { Two shes want water. ?? }\end{array}$ & $\begin{array}{l}\text { Two Katherines want cof- } \\
\text { fee. }\end{array}$ \\
\hline *Some shes want water. & $\begin{array}{l}{ }^{*} \text { Some Katherines want } \\
\text { coffee. }\end{array}$ & *Some shes want water. & $\begin{array}{l}\text { Some Katherines want } \\
\text { coffee. }\end{array}$ \\
\hline $\begin{array}{l}{ }^{*} \text { The she from the shelter } \\
\text { wants water. }\end{array}$ & $\begin{array}{l}{ }^{*} \text { The Katherine from yoga } \\
\text { class wants coffee. }\end{array}$ & $\begin{array}{l}{ }^{*} \text { The she from the shelter } \\
\text { wants water. }\end{array}$ & $\begin{array}{l}\text { The Katherine from yoga } \\
\text { class wants coffee. }\end{array}$ \\
\hline *Shes enjoy sleeping. & ${ }^{*}$ Katherines are classy. & $\begin{array}{l}\text { Shes need to be spayed, hes } \\
\text { neutered. ?? }\end{array}$ & Katherines are classy. \\
\hline *The she wants water. & $\begin{array}{l}{ }^{*} \text { The Katherine wants cof- } \\
\text { fee. }\end{array}$ & ${ }^{*}$ The she wants water. & $\begin{array}{l}\text { The Katherine wants cof- } \\
\text { fee. }\end{array}$ \\
\hline She wants water. & Katherine wants coffee. & ${ }^{*}$ She wants water. & ${ }^{*}$ Katherine wants coffee. \\
\hline
\end{tabular}

Here we see the same distribution for referential names and pronouns, but a different distribution for predicates. I find almost all of the so-called predicative occurrences of pronouns highly non-standard and would judge most ungrammatical. Those flagged with question marks strike me as only barely acceptable. It is curious that even with a single determiner like 'a', only certain sentences seem acceptable: 'We adopted a she' is fine; 'A she wants water' less than fine. This suggest that 'she' is acceptable only in some environments. It is a case of what Delgado usefully describes as a partial conversion.

Here is a summary of the distribution of pronouns for some determiners and modifiers discussed in \$\$8-13:

\begin{tabular}{|l|l|l|l|}
\hline $\begin{array}{l}\text { *That she wants water. } \\
\text { (Deictic, anaphoric) }\end{array}$ & $\begin{array}{l}\text { *That Katherine wants } \\
\text { coffee. } \\
\text { (Deictic, anaphoric) }\end{array}$ & $\begin{array}{l}\text { That she needs water. ?? } \\
\text { (Deictic, anaphoric) }\end{array}$ & $\begin{array}{l}\text { That Katherine wants cof- } \\
\text { fee. } \\
\text { (Deictic, anaphoric) }\end{array}$ \\
\hline $\begin{array}{l}* \text { That she is so special. } \\
\text { (Affective) }\end{array}$ & $\begin{array}{l}\text { That Katherine is so spe- } \\
\text { cial. } \\
\text { (Affective) }\end{array}$ & $\begin{array}{l}{ }^{*} \text { That she is so special. } \\
\text { (Affective) }\end{array}$ & $\begin{array}{l}\text { That Katherine is so spe- } \\
\text { cial. } \\
\text { (Affective) }\end{array}$ \\
\hline $\begin{array}{l}{ }^{*} \text { Goddamn she ignored me. } \\
\text { (Bare expressive) }\end{array}$ & $\begin{array}{l}\text { Goddamn Katherine ig- } \\
\text { nored me. } \\
\text { (Bare expressive) }\end{array}$ & $\begin{array}{l}{ }^{*} \text { The goddamn she bit me. } \\
\text { (Bare expressive) }\end{array}$ & $\begin{array}{l}\text { The goddamn Katherine } \\
\text { ignored me. } \\
\text { (Bare expressive) }\end{array}$ \\
\hline $\begin{array}{l}* \text { Poor she has been ill. } \\
\text { (Bare modifier) }\end{array}$ & $\begin{array}{l}\text { Poor Katherine has been } \\
\text { ill. } \\
\text { (Bare modifier) }\end{array}$ & $\begin{array}{l}\text { *The shortest she needs } \\
\text { water. (Restrictive modi- } \\
\text { fier) }\end{array}$ & $\begin{array}{l}\text { The shortest Katherine } \\
\text { wants coffee. } \\
\text { (Restrictive modifier) }\end{array}$ \\
\hline
\end{tabular}

While names take affective demonstratives and possessives, bare expressives, and bare modifiers, pronouns combine with none of them. Schoubye's pronouns-as-predicates again exhibit a starkly different distribution with deictic, anaphoric, and affective demonstratives, bare expressives, and prenominal restrictive modifiers. This should discourage accounting for names on analogy with pronouns. 
tent with names will possess knowledge of the unstated bridging premise that Katherine is a Katherine, for they will know that whoever 'Katherine' refers to is a Katherine, is a person called 'Katherine'. Such knowledge does not have to be cashed out in terms of the semantic content of the name. Our knowledge that Katherine is a Katherine is analogous to our knowledge that cats are called 'cats', knowledge that must be appealed to in order to explain the intuitive validity of these:

\section{Argument 3}

The cat wants water.

Therefore, at least one thing called 'cat' wants water.

\section{Argument 4}

Nothing called 'cat' wants water.

There exists at least one thing called 'cat'.

Therefore, the cat does not want water.

Knowledge that cats are called 'cats' and Katherine is a Katherine both constitute metalinguistic knowledge any reflective speaker of the language would possess. Yet it does not derive from the semantic content of 'cat' and need not derive from the semantic content of 'Katherine'.

The virtues of our syntactically grounded argument for referentialism extend beyond its power. By appealing to syntax to demonstrate the inadequacy of predicativism, we thereby put ourselves in the right position to focus upon the formation of an adequate referentialist semantic theory, to determine whether it ought to be purely Millian, indexicalist, or variabilist, decide if names systematically possess presuppositions, and resolve the problem of empty names. These are matters I have not even broached. I intentionally neglect them here because I regard them as best handled separately. In particular, I wish to discourage the current trend to measure the worth of a specific referentialist semantic proposal by whether it unifies the semantics as well as predicativism. If predicativism conflicts with the correct syntactic data, we need a completely different metric for theory evaluation.

I have argued that names are referential expressions whose interaction with the determiner system is limited, different in kind from that of count nouns, including collective 'names'. Names' syntactic distribution makes sense of their semantic properties: they resist determiners and modifiers that must function restrictively. Consequently, names and collective 'names' cannot be assimilated into a single syntactic class. My argument for these claims has been simple: I have advanced a robust set of syntactic data indicating dual syntactic distributions, typically at odds, for names and collective 'name' count nouns. This set of data is incompatible with that advanced within the Syntactic Rationale in favor of thepredicativism, and is difficult for any version of predicativism to accommodate.

While my position is at odds with predicativism, my argument is remarkably similar to the-predicativists' Syntactic Rationale. Each embraces the assumption that names and count nouns are classified by their syntactic properties. Each aspires to account for a wide range of syntactic data. Each evaluates theories in terms of their capacity to explain it. The central disparity concerns the data. I hope to have shown it is referentialism that best explains the phenomena. 


\section{REFERENCES}

Acton, Eric and Potts, Christopher. 2014. That straight talk: Sarah Palin and the sociolinguistics of demonstratives. Journal of Sociolinguistics 18: 3-31.

Bach, Kent. 2002. Giorgione was so-called because of his name. Philosophical Perspectives 16: 73-103.

Borer, Hagit. 2005. Structuring sense Volume 1: In name only. Oxford: Oxford University Press.

Burge, Tyler. 1973. Reference and proper names. Journal of Philosophy 70: 425-39.

Carlson, Gregory. 1977. Reference to kinds in English. Ph.D thesis, University of Massachusetts, Amherst.

Chomsky, Noam. 1965. Aspects of the theory of syntax. Cambridge: MIT Press.

Cumming, Samuel. 2008. Variablism. Philosophical Review 117: 525-554.

Delgado, Laura. 2018. Between singularity and generality: The semantic life of proper names, forthcoming in Linguistics and Philosophy.

Elbourne, Paul. 2005. Situations and individuals. Cambridge: MIT Press.

Elugardo, Reinaldo. 2002. The predicate view of proper names. In G. Preyer and G. Peter, eds., Logical form and language, pp. 467-503. Oxford: Oxford University Press.

Fara, Delia Graff. 2015a. Names are predicates. Philosophical Review 124: 59-117.

-. 2015b. A problem for predicativism solved by predicativism. Analysis 75: 251-297.

—. 2015c. 'Literal' uses of proper names. In Andrea Bianchi, ed., On reference, pp. 251-279. Oxford: Oxford University Press.

García-Carpintero, Manuel. 2017. The Mill-Frege theory of proper names. Mind, doi.org/10.1093/mind/ fzx010

Geurts, Bart. 1997. Good news about the description theory of names. Journal of Semantics 14: 319-48.

Ghomeshi, Jila and Diane Massam. 2005. The dog, the Moon, the Hague, and Canada. Proceedings of the 2005 annual conference of the Canadian Linguistic Association, pp. 1-12.

Gray, Aidan. 2017. Names in strange places. Linguistics and Philosophy 40: 429-472.

Green, John. 2006. An abundance of Katherines Dutton Books.

Hinzen, Wolfram. 2016. Linguistic evidence against predicativism. Philosophy Compass 11(10): 591-608.

Huddleston, Rodney and Geoffrey Pullum. 2002. The Cambridge grammar of the English language Cambridge: Cambridge University Press.

Jeshion, Robin. 2015a. Names not predicates. In Andrea Bianchi, ed., On reference, pp. 225-250 Oxford: Oxford University Press.

-. 2015b. A rejoinder to Fara's 'Literal' uses of proper names. In Andrea Bianchi, ed., On reference, pp. 280294. Oxford: Oxford University Press.

-. 2015c. Referentialism and predicativism about names. Erkenntnis 80:363-404.

-. 2017. 'The' problem for The-predicativism. Philosophical Review 126: 219-240.

King, Jeffrey. 2006. Singular terms, reference, and methodology in semantics. Philosophical Issues, 16: 141161.

Leckie, Gail. 2013. The double life of proper names. Philosophical Studies 165: 1139-1160.

Lee, Junhyo. 2018. On the asymmetry between names and count nouns, manuscript.

Longobardi, Giuseppe. 1994. Reference and proper names. Linguistic Inquiry 25: 609-665.

Matushansky, Ora. 2005. Call me Ishmael. In E. Maier, C. Bary, and J. Huitink, eds., Proceedings of Sinn und Bedeutung 9: 226-240. Nijmegen: The Nijmegen Centre of Semantics (NCS).

-. 2006. Why Rose is the Rose: On the use of definite articles in proper names. In O. Bonami and P. Cabredo Hofherr, eds., Empirical issues in syntax and semantics 6: 285-307.

-. 2015. The other Francis Bacon: On non-bare proper names. Erkenntnis 80: 335-362.

Pelczar, Michael, and Joe Rainsbury. 1998. The indexical character of names. Synthese 114: 293-317.

Perry, John. 2012. Reference and reflexivity, $2^{\text {nd }}$ Edition, Stanford: CSLI Publications.

Potts, Christopher. 2005. The logic of conventional implicatures. Oxford: Oxford University Press.

— and Florian Schwarz. 2010. Affective 'this'. Linguistic Issues in Language Technology 5:1-30. 
Pullum, Geoffrey. 2006. Obligatory adjectives and optional articles? Language Log, http://itre.cis.upenn. edu/ myl/languagelog/archives/003812.html

Rami, Dolf. 2013. On the unification argument for the predicate view of proper names. Synthese 191(5): $1-22$.

-. 2014. The use-conditional indexical conception of proper names. Philosophical Studies 168: 119-150.

-. 2016. Names, naming, and name-using practices. In P. Stalmaszczyk and L. Fernández Moreno, eds., Philosophical Approaches to Proper Names, 55-92.

Rothschild, Daniel. 2007. Presuppositions and scope. Journal of Philosophy 104(2): 71-106.

Sawyer, Sarah. 2010. A modified predicate theory of proper names. In S. Sawyer, ed., New Waves in Philosophy of Language, pp. 206-225. Hampshire: Palgrave Macmillan.

Schlenker, Philippe. 2007. Expressive presuppositons. Theoretical Linguistics 33(2): 237-45.

Schoubye, Anders. 2017. Type ambiguous names. Mind 126(503): 715-767.

Sloat, Clarence. 1969. Proper nouns in English. Language 45/1: 26-30.

Soames, Scott. 2002. Beyond rigity. Oxford: Oxford University Press.

Stanley, Jason and Zoltan Gendler Szabo. 2000. On quantifier domain restriction. Mind and Language 15: 219-261.

Wolter, Lynsey Kay. 2006. That's that: The semantics and pragmatics of demonstrative noun phrases. Ph.D Thesis, UC Santa Cruz.

Robin Jeshion is Professor of philosophy at University of Southern California. Previouisly, she taught at Yale University and University of California, Riverside, and has been a Visiting Scholar at Institut Jean Nicod and a Fellow at the Center for Advanced Study in the Behavioral Sciences.

Address: Mudd Hall Room 113. School of Philosophy. University of Southern California. 3709 Trousdale Parkway. Los Angeles, California, USA 90089-0451

E-mail: jeshion@usc.edu 